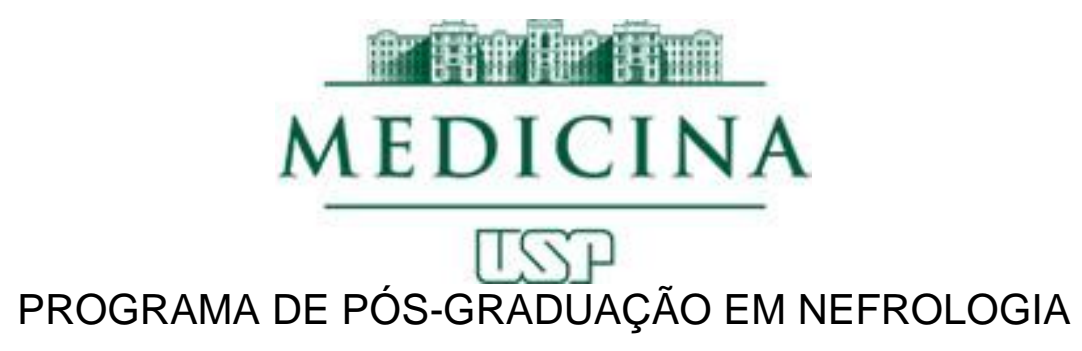

\title{
ASSOCIAÇÃO ENTRE FUNÇÃO ENDOTELIAL, AGREGABILIDADE PLAQUETÁRIA, INJÚRIA RENAL AGUDA E EVENTOS CARDIOVASCULARES EM PACIENTES SUBMETIDOS A CIRURGIAS VASCULARES
}

\begin{abstract}
Dissertação apresentada à Faculdade de Medicina da Universidade de São Paulo para obtenção do título de Mestre em Ciências Programa de Nefrologia
\end{abstract}

Orientadora: Dra. Etienne Maria

Vasconcellos de Macedo

São Paulo 


\section{Dados Internacionais de Catalogação na Publicação (CIP) \\ Preparada pela Biblioteca da \\ Faculdade de Medicina da Universidade de São Paulo}

Creprodução autorizada pelo autor

Teixeira, Maurício Brito

Associação entre função endotelial, agregabilidade plaquetária, injúria renal aguda e eventos cardiovasculares em pacientes submetidos a cirurgias vasculares / Maurício Brito Teixeira. -- São Paulo, 2017.

Dissertação(mestrado)--Faculdade de Medicina da Universidade de São Paulo.

Programa de Nefrologia.

Orientadora: Etienne Maria Vasconcellos de Macedo.

Descritores: 1.Lesão renal aguda 2.Doenças cardiovasculares 3.Doenças vasculares 4.Mortalidade 5.Agregação plaquetária 6.Endotélio vascular 
Nome: TEIXEIRA, Maurício Brito

Título: Associação entre função endotelial, agregabilidade plaquetária, injúria renal aguda e eventos cardiovasculares em pacientes submetidos a cirurgias vasculares

Dissertação apresentada à Faculdade de Medicina da Universidade de São Paulo para obtenção do título de Mestre em Ciências

Aprovado em:

Banca Examinadora

Prof. Dr.

Instituição:

Julgamento:

Prof. Dr.

Instituição:

Julgamento:

Profa. Dra.

Instituição:

Julgamento: 


\section{Dedicatória}

Aos meus pais, José e Edna, que desde tenra idade me ensinaram valores que carrego por toda minha vida. Eternamente serei grato. Saudades!

Às minhas irmãs, Tatiane e Larissa, que não perderam a leveza apesar de tantas superfícies ásperas. Vocês são meus exemplos!

Aos meus padrinhos, Ivan e Braulina, que souberam estar presentes e atuantes quando eu mais precisei.

À minha esposa Sheila, pela paciência comigo ao longo destes anos. Obrigado por apostar em nós dois, digo, nós três!

Ao meu filho Heitor, que eu consiga lhe transmitir que o maior sentido da vida é ser feliz. O resto pode esperar! 


\section{Agradecimentos}

À minha orientadora, Dra. Etienne Macedo, exemplo de profissional. Agradeço pela paciência em orientar-me no caminho da pesquisa.

À Dra. Daniela Calderaro, por viabilizar todo o projeto. Pela leveza no incentivo com palavras de apoio nas diversas fases da pesquisa.

Aos doutores Adriano Martins, Dimitri Flores e Licurgo Pamplona, médicos que, provavelmente sem o saberem, fizeram uma grande diferença em minha carreira.

À Dra Yvoty Alves que me orientou na nefrologia e incentivou a continuar no caminho da pesquisa.

A Pedro e Eliana, por sempre estarem presentes, ajudando os pós-graduandos.

A Fátima Libânio, por facilitar a coleta de dados laboratoriais através do sistema.

Às colegas de pós-graduação, Deane, Luiza e Camila, por compartilharem as dificuldades da concepção deste trabalho.

Ao CNPq pelo apoio financeiro e incentivo à pesquisa. 
Esta dissertação está de acordo com as seguintes normas, em vigor no momento desta publicação:

Referências: adaptado de International Committee of Medical Journals Editors (Vancouver).

Universidade de São Paulo. Sistema Integrado de Bibliotecas da USP. Diretrizes para apresentação de dissertações e teses da USP: parte IV (Vancouver); Vânia Martins Bueno de Oliveira Funaro... [et al.]. - 3 ed. rev. ampl. Mod. São Paulo: SiBi/ USP, 2016. 100p.

Abreviaturas dos títulos dos periódicos de acordo com List of Journals Indexed in Index Medicus. 


\section{SUMÁRIO}

Lista de abreviaturas e siglas

Lista de tabelas

Resumo

Summary

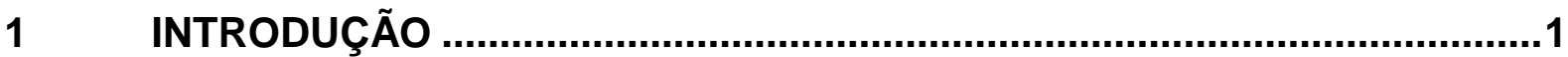

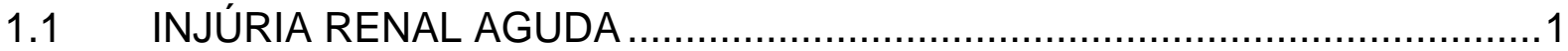

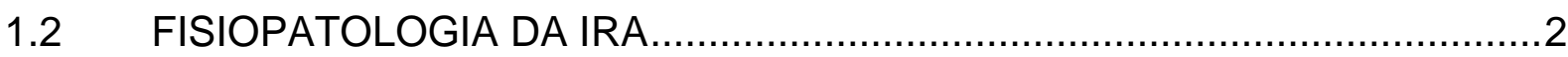

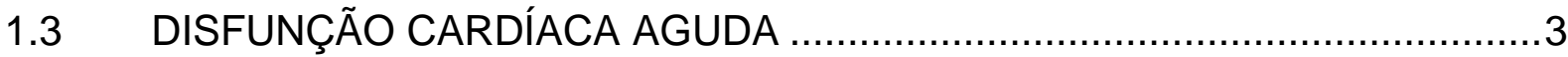

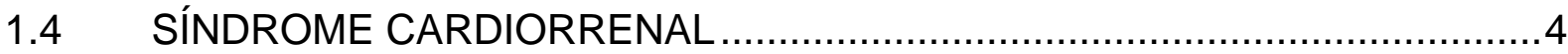

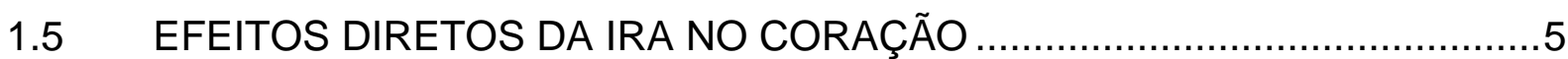

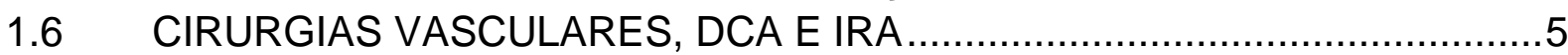

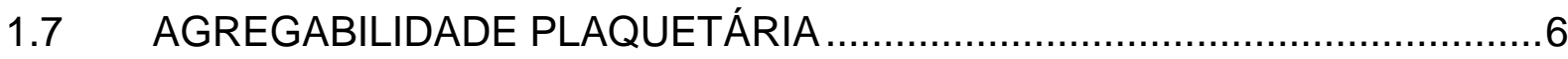

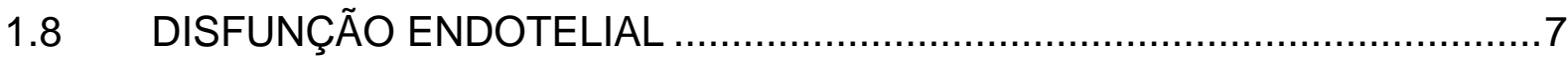

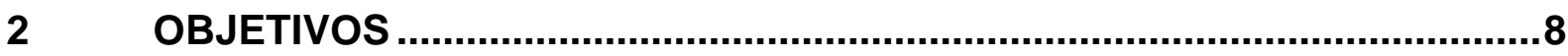

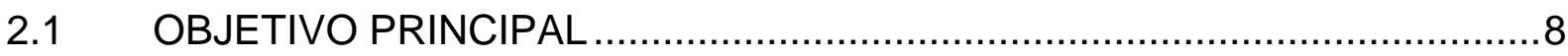

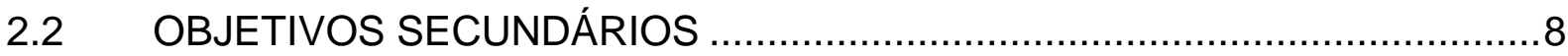

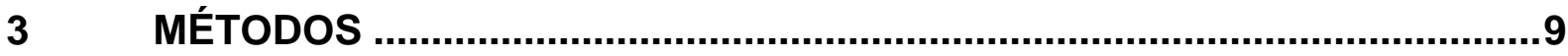

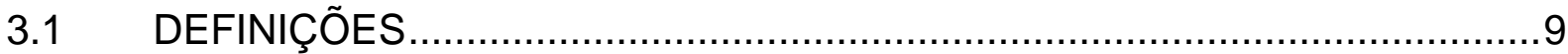

3.1.1 Injúria Renal Aguda (IRA) 9

3.1.2 Creatinina basal (SCr de base) 10

3.1.3 Recuperação da função renal 10

3.1.4 Avaliação de risco perioperatório 10

3.1.5 Cell Saver 11

3.1.6 Evento Hemorrágico 11

3.1.7 Diabetes, Hipertensão e Dislipidemia 11

3.1.8 Evento cardiovascular 11

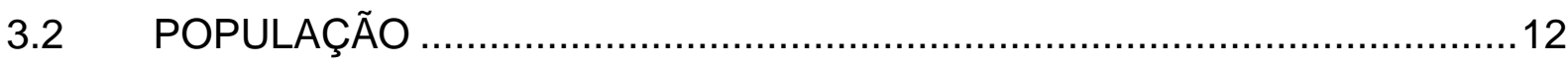

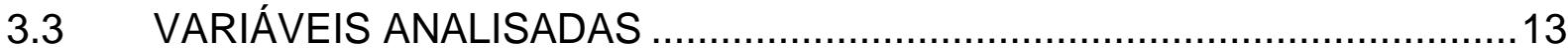

3.3.1 Medida da Hiperemia Reativa e da Dilatação Mediada pelo Fluxo 13

3.3.2 Teste da Agregabilidade Plaquetária 13

3.3.3 Primeiros 07 dias de pós-operatório 13

3.4 ANÁLISE ESTATÍSTICA E CÁLCULO DA AMOSTRA ............................14

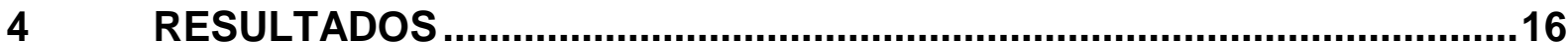

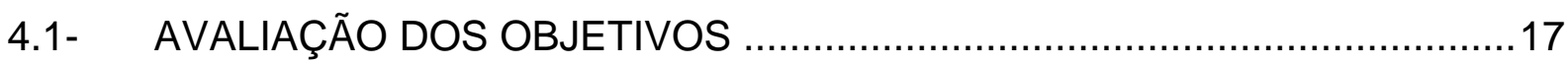


4.1.1 Avaliar a associação entre a presença de comorbidades com a incidência

de IRA:

4.1.2 Avaliar a associação entre o tipo de cirurgia vascular e fatores perioperatórios com o desenvolvimento de IRA:

4.1.3 Avaliar se o marcador de função endotelial como a Dilatação Mediada por Fluxo (FMD) pode funcionar como preditor de risco para o desenvolvimento de Injúria Renal Aguda nos pacientes que serão submetidos a cirurgias vasculares:

4.1.4 Avaliar se a medida da agregabilidade plaquetária pode funcionar como preditor de risco para o desenvolvimento de Injúria Renal Aguda nos pacientes que serão submetidos a cirurgias vasculares:

4.1.5 Analisar se os pacientes que desenvolveram IRA pelos critérios do KDIGO na primeira semana de pós-operatório evoluem ou estão associados com um aumento de eventos cardiovasculares e se houve relação temporal entre Injúria Renal Aguda e Evento Cardiovascular. 25

4.1.6 Avaliar se, nos pacientes submetidos a cirurgias vasculares, 0 diagnóstico

e a gravidade da IRA estão associados a pior prognóstico, como maior tempo de internação e mortalidade.

4.1.7 Recuperação da função renal 31

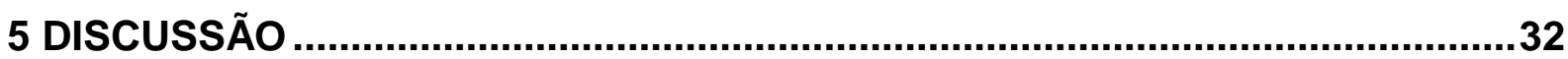

5.1 A INJÚRIA RENAL AGUDA NAS CIRURGIAS VASCULARES 32

5.2 DILATAÇÃO MEDIADA PELO FLUXO COMO PREDITOR DE INJÚRIA RENAL AGUDA

5.3 AGREGABILIDADE PLAQUETÁRIA COMO PREDITOR DE INJÚRIA RENAL AGUDA

5.4 ASSOCIAÇÃO ENTRE INJÚRIA RENAL AGUDA E EVENTOS CARDIOVASCULARES 


\section{LISTA DE ABREVIATURAS E SIGLAS}

ACP

ADQI

AKIN

ATP

AVCi

BRA

CaPPesq

COX-1

DAIC

DCA

DM

ECG

ESRD

FE

FMD

HCFMUSP

American Cardiology perioperative guidelines

Acute Dialysis Quality Initiative

Injúria Renal Aguda

Trifosfato de Adenosina

Acidente vascular cerebral isquêmico

Bloqueador do Receptor da Angiotensina

Comissão de Ética para Análise de Projetos de Pesquisa

Substrato da cicloxigenase 1

Disfunção Aguda da Insuficiência Cardíaca

Disfunção Cardíaca Aguda

Diabetes mellitus

Eletrocardiograma

Risk-Injury-Failure-Loss

Fração de Ejeção

Dilatação Mediada por Fluxo

Hospital das Clínicas da Faculdade de Medicina da Universidade de São Paulo

ICAM-1 Molécula de adesão intercelular - 1

IECA Inibidor da Enzima Conversora de Angiotensina

IL-1 Interleucina 1

INCOR Instituto do Coração

IRA

Injúria Renal Aguda

KDIGO Kidney Disease Improving Global Outcome

MDRD Modification of Diet in Renal Disease

NO Óxido Nítrico

PCR Proteína C Reativa

SCA Síndrome Coronariana Aguda

SCR Síndrome Cardiorrenal

SRAA Sistema Renina Angiotensina Aldosterona

TCLE Termo de Consentimento Livre e Esclarecido

TNF Fator de Necrose Tumoral

UTI Unidade de Terapia Intensiva 


\section{LISTA DE FIGURAS}

Figura 1 - Representação gráfica da seleção dos pacientes 16

Figura 2 - Relação entre o FMD e o Clearance de Creatinina conforme o MDRD.

Figura 3 - Relação entre FMD e IRA conforme o KDIGO máximo atingido nos primeiros 7

dias de pós-operatório.

Figura 4 - Relação entre o número de plaquetas e o Clearance de Creatinina conforme o MDRD.

Figura 5 - Relação entre a agregabilidade plaquetária expressa em Ohms após a administração do ácido araquidônico e a contagem total do número de plaquetas.

Figura 6 - Relação entre a agregabilidade plaquetária expressa em Ohms após a administração do ácido araquidônico e a gravidade da IRA conforme o KDIGO máximo atingido nos primeiros 7 dias de pós-operatório.

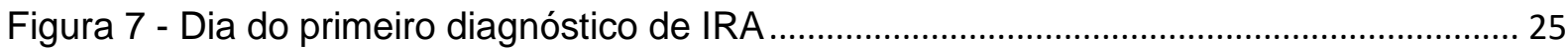

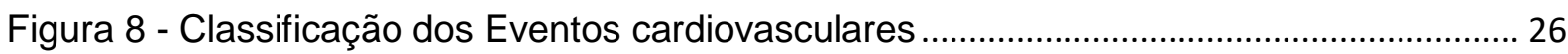

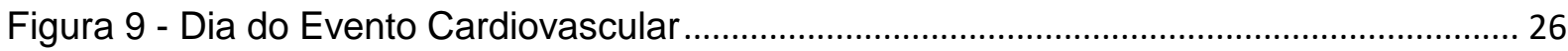

Figura 10 - - Relação entre o diagnóstico de IRA e Evento Cardiovascular ............................. 27

Figura 11 - Relação entre a classificação de IRA e Evento Cardiovascular............................. 27

Figura 12 - Tempo médio de internação na UTI conforme classificação da IRA pelo ............. 29

Figura 13 - - Boxplot comparativo dos dias de internação na UTI............................................ 30

Figura 14 - Mortalidade geral de acordo com os grupos de gravidade. .................................... 31 


\section{LISTA DE TABELAS}

Tabela 1 - Comparação dos estágios da IRA pelos sistemas RIFLE e AKIN ...........................1

Tabela 2 - Classificação da Síndrome Cardiorrenal (SCR) ..........................................................4

Tabela 3 - Características demográficas dos pacientes: ........................................................ 17

Tabela 4 - Características clínicas dos pacientes conforme sua classificação em Injúria

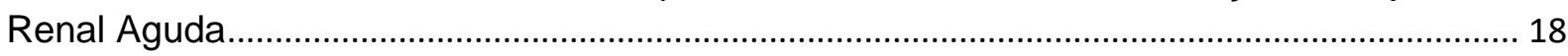

Tabela 5 - Características clínicas dos pacientes conforme a gravidade da Injúria Renal

Aguda pelo KDIGO........................................................................................................ 18

Tabela 6 - Características laboratoriais dos pacientes conforme sua classificação da Injúria

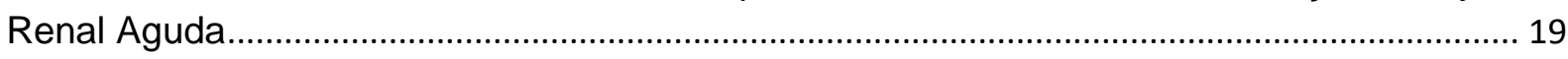

Tabela 7 - Tipo de cirurgia, variáveis do intraoperatório e a classificação de Injúria ............. 20

Tabela 8 - Agregabilidade plaquetária em Ohms após administração do ácido araquidônico

e Estágios de função renal conforme o clearance de creatinina. .............................................. 23

Tabela 9 - Resultado da análise multivariada dos fatores preditores independentes para

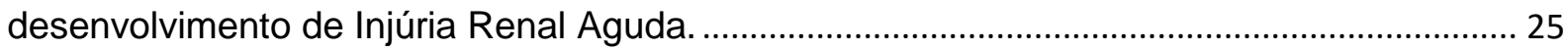

Tabela 10 - Resultado da análise univariada dos fatores preditores para desenvolvimento 28 de Evento Cardiovascular.

Tabela 11 - Características gerais dos pacientes conforme sua classificação da Injúria

Renal Aguda e Evento Cardiovascular .................................................................................. 29

Tabela 12 - Características laboratoriais dos pacientes conforme sua classificação da ..30 Injúria Renal Aguda e Evento Cardiovascular 


\section{RESUMO}

Teixeira MB. Associação entre função endotelial, agregabilidade plaquetária, injúria renal aguda e eventos cardiovasculares em pacientes submetidos a cirurgias vasculares. [dissertação]. São Paulo: Faculdade de Medicina da Universidade de São Paulo; 2017.

INTRODUÇÃO: A Injúria Renal Agurda (IRA) é uma síndrome com morbidade e mortalidade elevadas. O desenvolvimento de IRA e disfunção cardíaca aguda (DCA) no período pós-operatório de cirurgias vasculares compartilham fatores de risco e mecanismos fisiopatológicos. Neste estudo, levantamos a hipótese que o desenvolvimento de IRA em pacientes submetidos a cirurgias vasculares aumentaria o risco de DCA. Também avaliamos a Dilatação mediada pelo Fluxo (FMD), como medida de disfunção endotelial e testes de agregabilidade plaquetária com o intuito de identificar características relacionadas ao mecanismo fisiopatológico que levam a estes eventos em pacientes submetidos a cirurgias vasculares. MÉTODOS: Utilizamos dados coletados prospectivamente de uma coorte de pacientes submetidos a revascularização periférica, aórtica ou carotídea. A injúria renal aguda e eventos cardiovasculares foram avaliados nos primeiros sete dias após a cirurgia. Em um subgrupo de pacientes, o Doppler da artéria braquial foi realizado antes do procedimento cirúrgico para acessar a Dilatação mediada pelo Fluxo (FMD). Em outro subgrupo, foram realizados testes de agregabilidade plaquetária. RESULTADOS: Dos 287 pacientes incluídos na análise, 102 apresentaram IRA e 59 tiveram eventos cardiovasculares (EvCv). O número de pacientes com EvCv foi progressivamente maior conforme a gravidade da IRA com base no KDIGO; 15\% no grupo sem IRA, $22 \%$ no KDIGO 1, 42,8\% no KDIGO 2 e 55\% no KDIGO 3, p <0,001. Os pacientes com IRA apresentaram maior permanência na UTI (2,5 vs. 6 dias) e uma maior taxa de mortalidade $(6,6$ versus $23,5 \%), p<0,001$. A taxa de mortalidade em pacientes com IRA e EvCv foi duas vezes a mortalidade de pacientes com EvCv apenas (47,1 vs 19,4\%). A mediana de FMD foi de 5,7\%, sem diferença entre os grupos IRA e não IRA, $p=0,6$. Uma maior agregabilidade plaquetária foi associada ao desenvolvimento de IRA (5 vs 6,9 $\Omega$ ). $\mathrm{Na}$ análise multivariada, a presença de IRC (clearance de creatinina $<60 \mathrm{ml} / \mathrm{min} / 1,73 \mathrm{~m}^{2}$ ), instabilidade hemodinâmica, evento cardiovascular e agregabilidade plaquetária foram preditores independentes de IRA. CONCLUSÃO: Este estudo confirmou que o desenvolvimento de injúria renal aguda e eventos cardiovasculares aumenta significativamente a morbidade e mortalidade de pacientes submetidos a cirurgia vascular eletiva. Nossos dados sugerem que a realização de testes de agregabilidadade plaquetária antes da cirurgia pode ser usada para avaliar a eficácia da terapia antiplaquetária e estratificar o risco de IRA e EvCv após a cirurgia vascular. 


\section{SUMMARY}

TEIXEIRA MB. Association between endothelial function, platelet aggregability, acute kidney injury and cardiovascular events in patients submitted to vascular surgeries. [dissertation]. São Paulo: "Faculdade de Medicina da Universidade de São Paulo"; 2017.

BACKGROUND: Acute Kidney Injury (AKI) is a common syndrome with increased morbidity and mortality. The development of AKI and acute cardiac dysfunction (ACD) in the post-operative period of vascular surgery share risk factors and pathophysiological mechanisms. In this study, we hypothesized that the development of $A K I$ in patients submitted to vascular surgeries would increase the risk of ACD. We also assessed the Flow-mediated Dilation (FMD), as a measure of endothelial dysfunction, and Platelet Aggregability tests to predict AKI and cardiovascular events in the early post-operative period of vascular surgeries. METHODS: We utilized a prospectively collected data from a cohort of patients undergoing peripheral, aortic or carotid revascularization. Acute kidney injury and cardiovascular events were assessed during the first seven days after surgery. In a subgroup of patients, brachial artery Doppler was performed prior to the surgery to access the Flow-Mediated Dilation (FMD). In another subgroup, platelet aggregability tests were performed. RESULTS: Of 287 patients included in the analysis, 102 had AKI and 59 developed cardiovascular events (CvEv). Number of patients with CvEv was progressively higher by maximum KDIGO stage during first week of surgery; $15 \%$ in the non-AKI group, $22 \%$ in KDIGO $1,42.8 \%$ in KDIGO 2 and $55 \%$ in KDIGO $3, p<0.001$. Patients with AKI had a longer ICU stay ( 2.5 vs. 6 days) and a higher mortality rate ( 6.6 vs. $23.5 \%), p<0.001$. Mortality rate in patients with $\mathrm{AKI}$ and $\mathrm{CvEv}$ was two-fold the mortality of patients with CvEv only $(47,1$ vs $19.4 \%)$. The median FMD was $5.7 \%$, with no difference between the AKI and non-AKI groups, $p=0.6$. Higher platelet aggregability was associated with AKI development (5 vs 6,9 $\Omega$ ). In the multivariate analysis, presence of CKD (creatinine clearance $<60 \mathrm{ml} / \mathrm{min} / 1,73 \mathrm{~m}^{2}$ ), hemodynamic instability, cardiovascular event and platelet aggregability were independent predictors of AKI. CONCLUSION: This study confirmed that the development of acute kidney injury and cardiovascular events significantly increase morbidity and mortality of patients undergoing elective vascular surgery. Our data suggests that Platelet Aggregability before surgery can be used to evaluate efficacy of antiplatelet therapy and stratify risk for AKI and CvEv after vascular surgery. 


\section{INTRODUÇÃO}

\subsection{INJÚRIA RENAL AGUDA}

A Injúria Renal Aguda (IRA) é uma síndrome caracterizada por uma redução abrupta da função renal com comprometimento da homeostase do organismo. Está associada a diversas etiologias e apresenta-se com diversas características, entre elas, alterações eletrolíticas e retenção hídrica. No paciente crítico, é uma complicação comum e está associada a um grande aumento da mortalidade, mesmo com pequenos graus de injúria. O diagnóstico e a taxa de mortalidade associada à IRA variam bastante na literatura, dependendo da definição utilizada(1, 2). Em 2004, o grupo Acute Dialysis Quality Initiative (ADQI) publicou novos critérios para tentar unificar as definições de IRA criando a classificação de Risk-Injury-Failure-Loss-ESRD (RIFLE)(3). Com esta padronização, houve um progresso significativo no estudo clínico da Injúria Renal Aguda, e a possibilidade de comparação entre os estudos publicados posteriormente. Alguns anos depois, o grupo Acute Kidney Injury Network propôs algumas mudanças na classificação e publicou em 2007 os critérios AKIN para Injúria Renal Aguda(4). Comparando as duas definições, temos o seguinte (Tabela 1):

\section{Tabela 1 - Comparação dos estágios da IRA pelos sistemas RIFLE e AKIN}

\begin{tabular}{|c|c|c|c|c|}
\hline $\begin{array}{l}\text { Estágio } \\
\text { RIFLE }\end{array}$ & $\begin{array}{l}\text { Aumento da } \\
\text { Creatinina } \\
\text { sérica pelo } \\
\text { RIFLE }\end{array}$ & $\begin{array}{l}\text { Critério de débito } \\
\text { urinário pelo RIFLE } \\
\text { e pelo AKIN }\end{array}$ & $\begin{array}{c}\text { Aumento de creatinina sérica } \\
\text { pelo AKIN }\end{array}$ & $\begin{array}{l}\text { Estágio } \\
\text { AKIN }\end{array}$ \\
\hline Risco & $\begin{array}{l}\geq 150 \text { até } \\
200 \%\end{array}$ & $\begin{array}{c}<0,5 \mathrm{ml} / \mathrm{kg} / \mathrm{h} \text { por } \\
6 \mathrm{~h}\end{array}$ & $\geq 0,3 \mathrm{mg} / \mathrm{dl}$ ou $\geq 150$ até $200 \%$ & 1 \\
\hline Injúria & $\begin{array}{l}>200 \text { até } \\
300 \%\end{array}$ & $\begin{array}{c}<0,5 \mathrm{ml} / \mathrm{kg} / \mathrm{h} \text { por }> \\
12 \mathrm{~h}\end{array}$ & >200 até $300 \%$ & 2 \\
\hline Falência & $>300 \%$ & $\begin{array}{c}<0,3 \mathrm{ml} / \mathrm{kg} / \mathrm{h} \text { por } \\
\geq 24 \mathrm{~h} \text { ou anúria } \geq \\
12 \mathrm{~h}\end{array}$ & $\begin{array}{c}>300 \% \text { ou creatinina sérica } \\
\text { maior ou igual a } 4,0 \mathrm{mg} / \mathrm{dl} \text { com } \\
\text { um aumento de pelo menos } 0,5 \\
\text { mg/dl ou necessidade de } \\
\text { Terapia Renal Substitutiva }\end{array}$ & 3 \\
\hline
\end{tabular}

Fonte: Adaptado de Bellomo R, et al. e Ronco C, et al. $(3,4)$

Ambos usam a mudança na creatinina sérica e o débito urinário para a classificação. São de fácil aplicação, classificam a IRA em diferentes níveis, e estudos 
posteriores mostraram que as duas classificações têm uma boa sensibilidade e especificidade(5). Em 2012, a fundação KDIGO (Kidney Disease Improving Global Outcome) publicou seu consenso de IRA que incorpora tais conceitos em sua definição com algumas pequenas modificações(6):

IRA é definida como:

- Aumento da Creatinina sérica $\geq 0,3 \mathrm{mg} / \mathrm{dl}$ em $48 \mathrm{~h}$ ou

- Aumento na Creatinina sérica $\geq 1,5$ vezes o basal em 07 dias ou

- Redução do volume urinário para menos de $0,5 \mathrm{ml} / \mathrm{kg} / \mathrm{h}$ por 6 horas

O estadiamento de gravidade segue os mesmos critérios propostos pelo AKIN.

\subsection{FISIOPATOLOGIA DA IRA}

Diversos mecanismos são descritos para explicar o desenvolvimento de IRA. Todos eles podem contribuir, de forma não excludente, para o evento final que é a lesão renal. Na teoria da isquemia-reperfusão, a injúria ocorre em múltiplas fases. Com a redução da perfusão, ocorre redução do ATP intracelular, formação de radicais livres, aumento do cálcio intracelular, alteração da borda em escova das células dos túbulos renais e apoptose. Quando ocorre a reperfusão, a atividade inflamatória desencadeada pela isquemia é responsável pelo recrutamento de neutrófilos e linfócitos que contribuem para a necrose celular(7).

Importante ressaltar que túbulos de diferentes néfrons drenam para um mesmo túbulo coletor. Desta forma, independente do mecanismo inicial de lesão, a obstrução de um único túbulo coletor pode levar à falência de filtração de diversos néfrons.

Alterações endoteliais também contribuem para a lesão com o aumento da permeabilidade vascular, ativação e recrutamento de leucócitos. A ativação do endotélio pela isquemia ou pela atividade inflamatória perpetua um ciclo com um aumento das moléculas de adesão ICAM-1 e P-selectina, facilitando a interação leucócito-endotélio, levando à maior produção de citocinas e recrutamento de macrófagos. Além disso, o endotélio produz fatores vasoativos com uma produção 
maior de potentes vasoconstrictores como a endotelina e redução de vasodilatadores como o óxido nítrico, levando a maior isquemia local(7-9).

A interação entre células endoteliais, células inflamatórias e plaquetas faz parte de um continuum que culmina com a redução da filtração glomerular. A lesão vascular pode comprometer a função renal de diversas maneiras como influenciando a reatividade vascular, alterando a função da barreira capilar, modulando as vias inflamatórias e de coagulação. A formação de micro trombos já foi descrita em modelos animais de IRA e em biópsias de transplantes renais(10), mas ainda há poucos estudos sobre essa via fisiopatológica.

As plaquetas já foram identificadas como células efetoras que potencializam a resposta inflamatória com a habilidade de manter um "cross-talk" entre leucócitos e células endoteliais. Quando ativadas, liberam mais de 300 proteínas que podem não só ativar o processo de trombose e aterosclerose como também podem estimular a apoptose do endotélio agravando ainda mais a IRA (11).

\subsection{DISFUNÇÃO CARDÍACA AGUDA}

O termo Disfunção Cardíaca Aguda (DCA) é bastante amplo e inclui condições bastante heterogêneas como a Disfunção Aguda da Insuficiência Cardíaca (DAIC), a Síndrome Coronariana Aguda (SCA), Arritmias e o Choque Cardiogênico. Uma das mais comuns das DCAs é a Disfunção Aguda da Insuficiência Cardíaca (DAIC) que pode ser definida como um início novo, gradual ou rápida piora da insuficiência cardíaca com sinais e sintomas necessitando terapia urgente(12). Estes sintomas são primariamente o resultado de congestão pulmonar severa, devido à elevada pressão de enchimento do ventrículo esquerdo (com ou sem baixo débito cardíaco). A DAIC pode ocorrer em pacientes com Fração de Ejeção (FE) preservada ou baixa. Condições cardiovasculares concomitantes como SCA, hipertensão, doença valvar, arritmias atriais e/ou condições não cardíacas (incluindo disfunção renal, diabetes, anemia) estão presentes com frequência e podem precipitar ou contribuir para a fisiopatologia desta síndrome(12). Embora os "gatilhos" exatos da descompensação hemodinâmica com posterior congestão não sejam conhecidos, o excesso de sal, a disfunção renal, a ativação neuro-hormonal e de citocinas e algumas drogas são fatores associados. 


\subsection{SÍNDROME CARDIORRENAL}

A Síndrome Cardiorrenal (SCR) é uma alteração fisiopatológica complexa do coração e dos rins em que a disfunção aguda ou crônica em um órgão pode induzir uma disfunção aguda ou crônica no outro. O órgão com a alteração primária pode ser tanto o coração quanto os rins. Desta forma, classifica-se a Síndrome Cardiorrenal em 05 tipos (Tabela 2):

\section{Tabela 2 - Classificação da Síndrome Cardiorrenal (SCR)}

SCR tipo 1 (Síndrome Cardiorrenal aguda)

SCR tipo 2 (Síndrome Cardiorrenal crônica)

SCR tipo 3 (Síndrome Renocardíaca aguda)

SCR tipo 4 (Síndrome Renocardíaca Crônica)

SCR tipo 5 (Síndrome Cardiorrenal Secundária)
Piora abrupta da função cardíaca (choque cardiogênico ou descompensação aguda da Insuficiência Cardíaca) levando à Injúria Renal Aguda.

Anormalidades crônicas na função cardíaca (Insuficiência Cardíaca Crônica) levando à Insuficiência renal crônica.

Piora abrupta da função renal (Injúria Renal Aguda ou Glomerulonefrite) causando Disfunção Cardíaca Aguda (Insuficiência Cardíaca, arritmia, edema pulmonar).

Doença Renal Crônica contribuindo com a piora da função cardíaca, hipertrofia cardíaca e/ou aumento do risco de eventos cardiovasculares adversos.

Condição sistêmica (diabetes, sepse) causando tanto a disfunção cardíaca quanto a renal.

Fonte: Adaptado de Ronco et al. (13)

O espectro da Síndrome Cardiorrenal tipo 3 prevê a disfunção cardíaca aguda que pode incluir uma insuficiência cardíaca com descompensação aguda, um infarto ou arritmias no contexto de IRA(14). As principais modificações sistêmicas que ocorrem quando há Injúria Renal Aguda e que podem alterar a função cardíaca são: 1) A oligúria que pode levar à sobrecarga hídrica e à retenção de sódio, contribuindo para a formação de edema, sobrecarga cardíaca, hipertensão, edema pulmonar, edema de mucosas, podendo levar ao retardo na absorção de drogas e nutrientes, além da disfunção miocárdica; 2) $O$ desequilíbrio eletrolítico pode contribuir para um aumento do risco de arritmias; 3) A acidemia parece causar vasoconstricção pulmonar, aumento na pós-carga do ventrículo direito e tem um efeito inotrópico negativo; 4) O acúmulo agudo de toxinas urêmicas que pode levar ao infarto do miocárdio e a outras disfunções(13-15).

Na sepse, a IRA também pode estar associada a mecanismos, como a disfunção dos leucócitos, subdose dos antibióticos, sobrecarga hídrica levando ao 
retardo na cicatrização e maior tempo de ventilação mecânica - todos aumentando o risco de novas infecções. Finalmente, há evidências de que a resolução do processo inflamatório é comprometida pela disfunção renal(8).

Os efeitos da Injúria Renal Aguda no coração podem ser divididos em diretos e indiretos.

\subsection{EFEITOS DIRETOS DA IRA NO CORAÇÃO}

Aparentemente há uma associação entre anormalidades cardíacas após a IRA com infiltração de neutrófilos, mediadores inflamatórios e apoptose de células cardíacas. A isquemia prolongada, seguida por reperfusão, induz à inflamação e apoptose levando a dano tissular e disfunção do órgão(16).

Durante a IRA, existe um aumento da quantidade tanto do TNF e da IL-1 cardíaca e sistêmica juntamente com um aumento da expressão do RNA mensageiro do ICAM-1, selectina, ativação do complemento, ativação do fator nuclear kB e dos receptores Toll-like, o que resulta na infiltração de neutrófilos no coração e na apoptose dos miócitos $(17,18)$.

Diversos estudos têm mostrado que um aumento nos níveis da Troponina sérica se correlaciona com pior prognóstico a curto e longo prazo da Disfunção Aguda da Insuficiência Cardíaca. Estudos preliminares sugerem que a hipóxia celular, a ativação do Sistema Renina Angiotensina Aldosterona (SRAA), do Sistema Adrenérgico, das citocinas e do óxido nítrico levam à morte celular (apoptose/necrose).

São necessários estudos que comprovem a presença e a magnitude da lesão miocárdica na DCA, prevenindo ou limitando tal lesão com intervenções agudas, o que pode melhorar o prognóstico em longo prazo.

\subsection{CIRURGIAS VASCULARES, DCA E IRA}

As patologias vasculares têm uma apresentação predominante em idosos. Embora tenha ocorrido um grande avanço nos cuidados perioperatórios, as cirurgias dos grandes vasos ainda estão relacionadas com grande morbidade e mortalidade, especialmente devido à Disfunção Cardíaca Aguda. A fisiopatologia da DCA 
associada a cirurgias vasculares é complexa, compreendendo a instabilidade da placa aterosclerótica e anormalidades na reatividade vascular(19, 20).

A IRA, por sua vez, pode ocorrer pelos mecanismos de isquemia-reperfusão, alterações inflamatórias, drogas, ou pelo uso de contraste iodado que é tão comum neste tipo de cirurgia. O uso de contraste iodado induz uma IRA devido à vasoconstricção renal diretamente relacionada à osmolaridade e ao volume do contraste utilizado e também pelo efeito citotóxico direto do agente com a geração de radicais livres(21).

Desta forma, a maior morbimortalidade das cirurgias vasculares pode ser explicada por algum fator comum que leve este paciente a ter uma predisposição maior a mais episódios de IRA e de DCA.

\subsection{AGREGABILIDADE PLAQUETÁRIA}

As plaquetas têm um papel primordial no progresso da aterosclerose e nos eventos cardiovasculares (22). Embora ainda não demonstrado, acredita-se também em seu papel no desenvolvimento da IRA, haja vista o crescimento de publicações tentando demonstrar o benefício da aspirina na prevenção do insulto renal. No entanto, sabemos que, mesmo em uso de antiagregantes, até $40 \%$ dos pacientes podem não estar com as suas vias de agregação plaquetária inibidas, não prevenindo eventos cardiovasculares (23), nem tendo efeitos benéficos na prevenção da IRA. Os testes da agregabilidade plaquetária, que já existem desde a década de 1960, ganharam força na pesquisa de quem são esses pacientes que podem não estar se beneficiando de tal terapia. Em suma, uma corrente elétrica é aplicada em um circuito com a amostra de sangue para ativar a agregação e, em seguida, mede-se a resistência elétrica à passagem de uma corrente de voltagem através do sangue. Posteriormente, o sangue é exposto a diferentes agonistas que estimulam a agregação como o ácido araquidônico e o colágeno em diferentes concentrações. 0 tampão plaquetário formado acrescenta uma resistência elétrica ao circuito que pode ser medida em ohms $(\Omega)$. Quanto maior a resistência, maior a agregação. Este teste é validado para avaliar o efeito da aspirina medindo a resistência gerada no circuito após a adição do ácido araquidônico, o substrato da cicloxigenase 1 (COX-1) que é inibida pela aspirina. Ao se adicionar o ácido araquidônico, como a via da COX 1 está 
inibida, não deveria haver maior agregação. Caso isto ocorra, pode indicar uma resistência à aspirina (24).

\subsection{DISFUNÇÃO ENDOTELIAL}

O endotélio foi considerado durante muito tempo uma barreira inerte aos elementos contidos no sangue. Entretanto, há evidências de que o endotélio seja um importante modulador do tônus, da hemostasia, da inflamação e do desenvolvimento da aterosclerose.

A disfunção endotelial é condição comum a várias patologias. Além da aterosclerose, ela também acontece na hipercolesterolemia, no diabetes, hipertensão, insuficiência cardíaca e no tabagismo. Em condições normais, o endotélio deve manter o vaso em um estado de vasodilatação. Entretanto, o endotélio tem a capacidade de responder a vários estímulos hemodinâmicos e a fatores produzidos localmente(7).

A avaliação da atividade endotelial está focada nos efeitos vasodilatadores do Óxido Nítrico (NO). Pode-se medir a função endotelial da artéria braquial (macrocirculação) com um Eco-Doppler ultrassom de alta resolução, determinando as respostas vasodilatadoras da artéria durante a Hiperemia Reativa (vasodilatação endotélio dependente) e após a administração de nitroglicerina sublingual (vasodilatação endotélio independente). Uma resposta alterada ao estímulo do NO endógeno (hiperemia) refletirá uma biodisponibilidade comprometida de $\mathrm{NO}$, ao passo que uma resposta diminuída ao que recebeu nitroglicerina, indica uma contratilidade diminuída da célula muscular lisa. As respostas alteradas às manobras indicadas têm sido relacionadas com o comprometimento da vasodilatação endotélio-dependente em artérias coronárias em diversos estudos(25-27).

Embora uma associação entre IRA e causas cardíacas de morbimortalidade possa ser mostrada e haja um embasamento fisiopatológico para o fato, ainda são necessários mais estudos para entender o tamanho do problema que a Síndrome Cardiorrenal representa e o seu impacto nos programas de saúde. Além disso, precisamos saber se, em pacientes cirúrgicos, uma disfunção predispõe à outra, e se há fatores comuns relacionados, como a disfunção endotelial e a agregabilidade plaquetária, que possam explicar a predisposição destes pacientes a desenvolverem IRA e DCA. 


\section{OBJETIVOS}

\section{1 - OBJETIVO PRINCIPAL}

- Analisar se os pacientes que desenvolveram IRA pelos critérios do KDIGO na primeira semana de pós-operatório apresentaram mais eventos cardiovasculares e se houve relação temporal entre IRA e evento cardiovascular.

\section{2 - OBJETIVOS SECUNDÁRIOS}

- Avaliar se, nos pacientes submetidos a cirurgias vasculares, o diagnóstico e a gravidade da IRA estão associados a pior prognóstico, como maior tempo de internação, uso de droga vasoativa e mortalidade.

- Avaliar a associação entre a presença de comorbidades com a presença de IRA e eventos cardiovasculares nos pacientes submetidos a cirurgias vasculares.

- Avaliar a associação entre o tipo de cirurgia vascular e fatores perioperatórios com o desenvolvimento de IRA e eventos cardiovasculares.

- Avaliar se marcadores de função endotelial como a Dilatação Mediada por Fluxo (FMD) podem ser utilizados como marcadores de risco para o desenvolvimento de Injúria Renal Aguda nos pacientes que serão submetidos a cirurgias vasculares.

- Avaliar se os pacientes com maior agregabilidade plaquetária que foram submetidos a cirurgias vasculares tiveram maior risco para o desenvolvimento de Injúria Renal Aguda. 


\section{MÉTODOS}

Com o objetivo principal de avaliar se a Insuficiência Renal Aguda apresentada por alguns pacientes no pós-operatório tem relação com a Disfunção Cardíaca, procuramos uma população que fosse de risco para desenvolver tais patologias e que não tivessem outros fatores confundidores como a sepse. Buscamos cirurgias que fossem realizadas eletivamente para também afastar a possibilidade de instabilidade prévia levando às disfunções. Além disso, deveriam ser pacientes que fizessem acompanhamento no hospital para que pudéssemos buscar nos prontuários, os exames do pré e do pós-operatório, principalmente os relacionados à função renal. Pensando nessa população, foi feita uma análise retrospectiva de dados coletados prospectivamente para o estudo "Análise funcional do endotélio no perioperatório de operações vasculares", conduzido de 2004 a 2009 e do estudo "Agregabilidade plaquetária e complicações cardiovasculares no perioperatório vascular" conduzido no período de 2009 a 2012, ambos no complexo do HCFMUSP pelo grupo de avaliação perioperatória do INCOR. Partindo dos dados que haviam sido coletados, buscamos as avaliações de função renal (creatinina, diurese e análise da urina) de antes e depois da cirurgia. Para avaliação da Creatinina de base, limitamos a busca no prontuário aos três meses prévios à cirurgia e, para avaliação de recuperação, buscamos até o final do primeiro ano de pós-operatório. O projeto foi aprovado pelo comitê de ética para análise de projetos em pesquisa da FMUSP (CaPPesq) com o número do parecer 1.076.622.

\subsection{DEFINIÇÕES}

\subsubsection{Injúria Renal Aguda (IRA)}

O diagnóstico e a gravidade da IRA foram definidos de acordo com o sistema de classificação KDIGO utilizando o critério da creatinina. A presença de IRA foi definida como uma elevação da Scr em $0,3 \mathrm{mg} / \mathrm{dL}$ em 48 horas ou um aumento percentual de $50 \%$ em relação a Scr de base em uma semana(6). 


\subsubsection{Creatinina basal (SCr de base)}

A SCr de base foi considerada como o menor valor da Scr nos três meses anteriores à cirurgia vascular. Para aqueles que não possuíam registro do valor da Scr prévia, foi considerado o primeiro valor durante a internação(28, 29).

\subsubsection{Recuperação da função renal}

A recuperação da função renal foi avaliada em médio prazo pela relação entre a última $\mathrm{Cr}$ do paciente entre 60 dias e um ano após a cirurgia e a Cr basal (última $\mathrm{Cr}$ entre 60 e 365 dias/ Cr basal). Uma relação menor que 1.2 foi considerada como recuperação total da função renal(30).

\subsubsection{Avaliação de risco perioperatório}

$\mathrm{Na}$ avaliação de risco cardiovascular, foram utilizados dois algoritmos bastante difundidos em nosso meio: o risco Lee e o algoritmo do American College of Physicians (ACP). O primeiro propõe a estratificação de risco perioperatório em quatro classes, de acordo com a presença das seguintes variáveis: cirurgia de alto risco intrínseco, história de insuficiência coronária crônica, história de insuficiência cardíaca congestiva, história de doença cérebro-vascular, insulinoterapia para controle de diabetes e $\mathrm{Cr}>2,0 \mathrm{mg} / \mathrm{dL}$. São considerados classe I de risco pacientes sem nenhuma dessas variáveis; classe II: presença de apenas uma destas variáveis; classe III: presença de duas destas variáveis; classe IV: pacientes com 3 ou mais destas variáveis(31, 32). O algoritmo ACP estratifica em 3 classes de riscos cirúrgicos atribuindo pontuações às seguintes variáveis: infarto prévio, história de angina, edema agudo prévio, presença de diabetes, hipertensão com hipertrofia severa do ventrículo esquerdo, alteração isquêmica do ST, cirurgia de emergência, suspeita de estenose de aorta crítica(33). 


\subsubsection{Cell Saver}

Tipo de transfusão autóloga que consiste na recuperação do sangue perdido durante uma cirurgia, processamento em uma máquina e reinfusão no paciente. Quantificou-se na cirurgia quantos mililitros de sangue foram recuperados por este método.

\subsubsection{Evento Hemorrágico}

Os eventos hemorrágicos foram classificados conforme os critérios TIMI em eventos maiores ou menores(34):

Evento hemorrágico maior: evento clínico de sangramento associado a uma redução na hemoglobina maior que $5 \mathrm{~g} / \mathrm{dL}$ ou $15 \%$ do hematócrito.

Evento hemorrágico menor: evento clínico de sangramento associado a uma redução na hemoglobina maior que 3 e menor que $5 \mathrm{~g} / \mathrm{dL}$ ou uma redução no hematócrito entre $9 \%$ a $\leq 15 \%$.

\subsubsection{Diabetes, Hipertensão e Dislipidemia}

Consideramos como portadores das patologias acima, os pacientes que autorreferiram ser portadores e faziam uso de medicações específicas para tal como hipoglicemiante oral ou insulina, anti-hipertensivo e hipolipemiante, respectivamente.

\subsubsection{Evento cardiovascular}

Consideramos como evento cardiovascular:

Infarto Agudo do Miocárdio: detecção de curva típica dos marcadores de necrose miocárdica com pelo menos um valor acima do percentil 99 do limite máximo de referência da troponina juntamente com sintomas de evento isquêmico ou o aparecimento de ondas $Q$ patológicas no eletrocardiograma (ECG) ou alterações no ECG indicativas de isquemia (supra ou infradesnível do segmento ST) ou nova alteração de contratilidade no Ecocardiograma. 
Angina instável: Sintomas isquêmicos com duração de pelo menos 20 minutos com ou sem alterações eletrocardiográficas e sem alteração nos marcadores de necrose miocárdica.

Elevação isolada da Troponina: Elevação da Troponina a valores acima do percentil 99 do limite superior do valor de referência sem sintomas de isquemia e sem alterações eletrocardiográficas. Foi utilizada a Troponina T ultrassensível (Roche).

Acidente vascular cerebral isquêmico (AVCi): Sinais de um AVCi confirmados através de um exame de imagem - tomografia ou ressonância.

Reoperação: Nova abordagem cirúrgica devido a complicações trombóticas da cirurgia inicial.

Óbito: Óbito por qualquer um dos eventos especificados acima. Uma vez classificado o evento como óbito, era retirado para análise do evento que o antecedeu. Por exemplo, se um paciente teve um AVCi e foi a óbito por complicação deste AVC, foi classificado como óbito e não mais como AVC.

\subsection{POPULAÇÃO}

Pacientes candidatos a cirurgia eletiva de revascularização periférica, de aorta ou de carótida foram considerados elegíveis. O Termo de Consentimento Livre e Esclarecido (TCLE) foi obtido quando o paciente foi orientado sobre a necessidade da cirurgia e o paciente foi devidamente esclarecido quanto à possibilidade de recusa de participação sem que isso afetasse no seu tratamento. $O$ protocolo do estudo e 0 TCLE foram aprovados pelo Comitê de Ética do Hospital - Protocolo número 1068/03 e 1065/09.

Os Critérios de exclusão foram: Evidência clínica de infecção, isquemia crítica do membro, eventos cardiovasculares ou cirurgias nos últimos 03 meses, câncer, insuficiência renal crônica com necessidade de diálise, ausência de dados referentes à função renal no prontuário ou o não preenchimento do Termo de Consentimento Livre e Esclarecido. Especificamente no grupo em que foi analisada a agregabilidade plaquetária, também fazia parte dos critérios de exclusão: o uso de outro antiagregante plaquetário que não fosse a aspirina, transfusão de plaquetas, tratamentos com varfarina, uso de anti-inflamatórios não esteroides, na última semana, contagem total de plaquetas menor que $100.000 / \mathrm{ml}$. 


\subsection{VARIÁVEIS ANALISADAS}

Dados referentes à identificação, sexo, idade, duração da internação hospitalar e da UTI, história clínica e patológica, medicações em uso pré-hospitalar, exames laboratoriais incluindo PCR, Hemograma, Troponina e Creatinina, além de Ecocardiograma. Em um grupo de pacientes também foi feito o Doppler da artéria braquial para acessar a Dilatação Mediada por Fluxo na consulta prévia à internação que ocorreu até um mês antes da cirurgia.

\subsubsection{Medida da Hiperemia Reativa e da Dilatação Mediada pelo Fluxo}

Foi feita análise morfológica de artéria braquial através de ultrassom-Doppler com o aparelho Acusson (Siemens Company), modelo Sequoia equipado com transdutor linear de alta resolução vascular $(7,5 \mathrm{MHz})$. Foram adquiridas imagens bidimensionais da artéria braquial na fossa antecubital no estado basal, durante o período da Hiperemia Reativa induzida por uma oclusão com um manguito no braço insuflado a uma pressão de $250 \mathrm{mmHg}$. Todas as imagens foram avaliadas off-line pelo mesmo investigador que estava cego em relação aos resultados clínicos.

\subsubsection{Teste da Agregabilidade Plaquetária}

Este teste foi feito antes da cirurgia com coleta do sangue em jejum, transportado em tubos de citrato a 3,2\% e o exame foi avaliado em até 180 minutos após a coleta através do Chronolog Corp, Havertown, Pa. A extensão da agregação foi medida em ohms $(\Omega)$ e indica a agregação plaquetária após a exposição a diferentes agonistas como o ácido araquidônico e o colágeno em diferentes concentrações.

\subsubsection{Primeiros 07 dias de pós-operatório}

Foram colhidos dados dos prontuários sobre a situação clínica do paciente: ventilação mecânica, instabilidade hemodinâmica, uso de droga vasoativa, eventos coronarianos, além de dados laboratoriais diários para avaliação da evolução laboratorial. 


\subsection{ANÁLISE ESTATÍSTICA E CÁLCULO DA AMOSTRA}

Para o cálculo da amostra, o desfecho primário foi a diferença de incidência de Disfunção Cardíaca Aguda entre os grupos com e sem Injúria Renal Aguda. O cálculo foi realizado utilizando o programa G*Power. Com base na literatura e em estudos prévios realizados na instituição, assumimos a incidência de DCA de 15\%. Para obter um nível de significância de $5 \%$ e poder de $90 \%$ de detectar um aumento na incidência de DCA para $25 \%$ no grupo com IRA, seriam necessários 158 pacientes.

Para a construção do banco de dados foi utilizada planilha eletrônica do Excel e a análise estatística foi realizada através do programa "IBM SPSS 20.0 for Windows". As variáveis categóricas foram apresentadas como valor absoluto e percentagem, e comparadas pelos testes de Fisher ou qui-quadrado. Os dados contínuos foram inicialmente comparados com a curva de Gauss através de testes de normalidade (Shapiro-Wilk e Kolmogorov-Smirnov) e determinados como paramétricos ou não paramétricos. As variáveis distribuídas normalmente foram sumarizadas através da média e desvio padrão enquanto as distribuídas em forma não-normal foram sumarizadas através da mediana e distância interquartílica (P25\% a P75\%). Para comparações de variáveis contínuas entre dois grupos, utilizamos os testes $\mathrm{t}$ de Student (distribuição normal) ou $U$ de Mann-Whitney (distribuição não normal).

Para avaliar se houve relação entre o diagnóstico de IRA e de DCA, foi construída uma tabela $2 \times 2$ e suas frequências foram comparadas com o teste quiquadrado. Para estabelecer qual evento recebeu o diagnóstico primeiro (IRA versus DCA), comparamos o tempo médio para diagnóstico de cada um dos eventos com o teste de Wilcoxon de amostras relacionadas.

Para as demais avaliações dos objetivos secundários, comparamos o diagnóstico e gravidade da IRA com comorbidades prévias, medicações utilizadas, risco perioperatório, tipo de cirurgia, tempo de internação e mortalidade através dos testes de qui-quadrado (variáveis categóricas) ou de Kruskal-Wallis (variáveis contínuas de amostras independentes).

Para avaliar se o FMD e a agregabilidade plaquetária podem funcionar como marcadores de risco para o desenvolvimento de Injúria Renal Aguda nos pacientes que foram submetidos a cirurgias vasculares, comparamos com gráficos de "boxplots" 
os diferentes grupos e através do teste de Kruskal-Wallis para amostras independentes.

Análise univariada de diversas variáveis foi feita para identificar possíveis fatores confundidores associados à DCA e mortalidade. Um $p$ considerado estatisticamente significante foi $<0,05$.

O modelo de regressão logística identificou os fatores preditores de Evento Cardiovascular e de IRA. Todas as variáveis univariadas com um $p<0,1$ foram selecionadas para a análise multivariada. A adequação do modelo foi feita com o teste de Hosmer-Lemershow. 


\section{RESULTADOS}

Na figura 1 é apresentado o fluxograma utilizado para a seleção dos pacientes. No estudo "Análise funcional do endotélio no perioperatório de operações vasculares" conduzido de 2004 a 2009 foram avaliados 96 pacientes e no estudo "Agregabilidade plaquetária e complicações cardiovasculares no perioperatório vascular" conduzido no período de 2009 a 2012 foram avaliados 191 pacientes. Todos foram submetidos a cirurgias vasculares em caráter eletivo.

\section{Figura 1 - Representação gráfica da seleção dos pacientes}

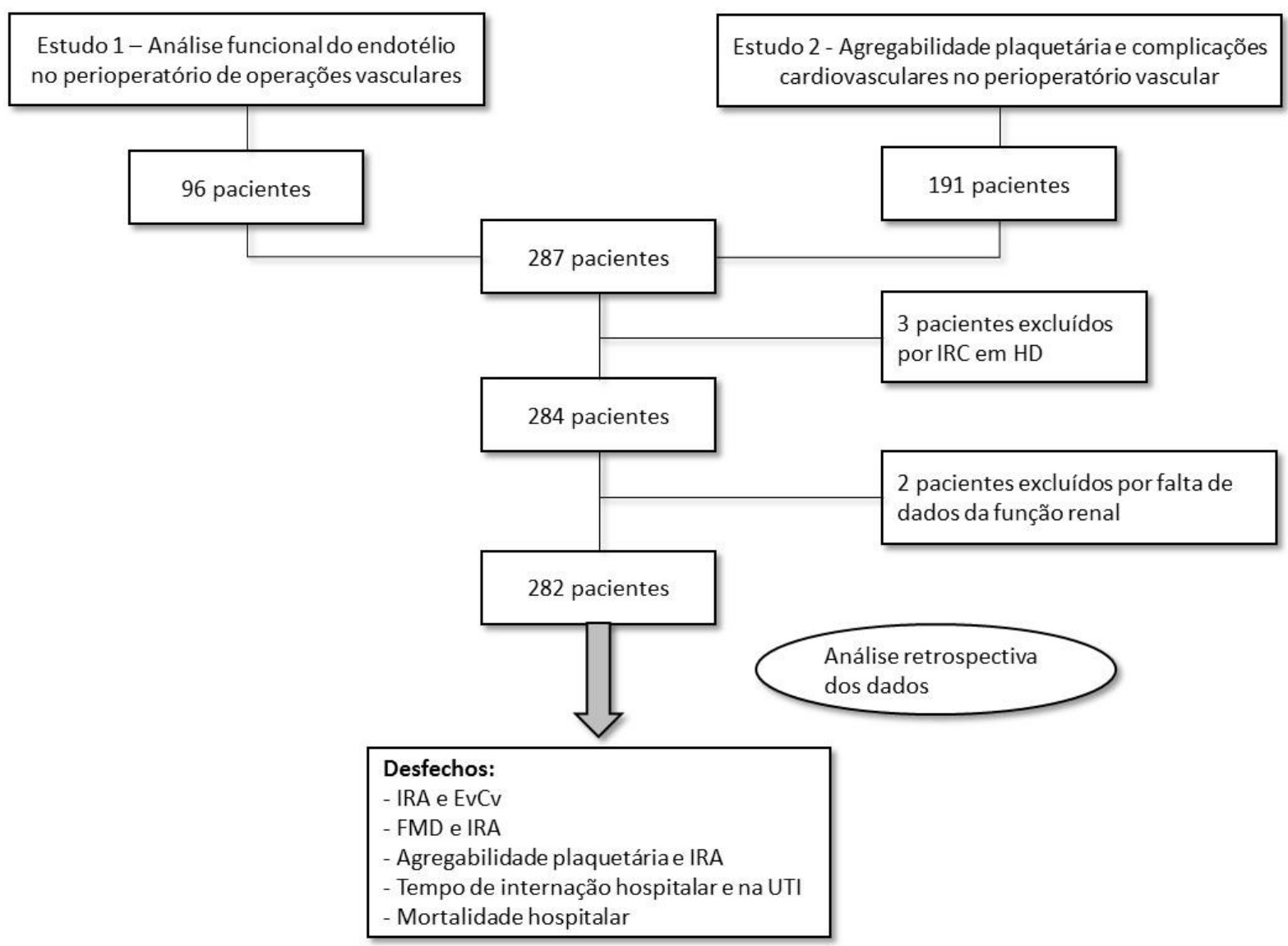

Nota: IRC, Insuficiência Renal Crônica; HD, Hemodiálise; IRA, Injúria Renal Aguda; EvCv, Evento Cardiovascular; FMD, Dilatação Mediada por Fluxo.

A idade média dos pacientes foi de $66,7 \pm 9,6$ anos. Setenta e dois por cento eram do sexo masculino. Oitenta e oito por cento eram hipertensos e vinte e três por cento eram diabéticos. Procedimentos convencionais (cirurgias abertas) foram a maioria $(55,7 \%)$ e as vasculopatias mais comuns foram na aorta $(45 \%)$. As características gerais dos pacientes estudados são mostradas na tabela 3 . 
Tabela 3 - Características demográficas dos pacientes:

\begin{tabular}{|c|c|}
\hline Características clínicas & \\
\hline $\begin{array}{l}\text { Idade, anos } \\
\text { Sexo masculino } \\
\text { Hipertensão } \\
\text { Dislipidemia } \\
\text { Diabetes }\end{array}$ & $\begin{array}{l}66,7 \pm 9,6 \\
203(72) \\
250(88,7) \\
200(70,9) \\
67(23,8)\end{array}$ \\
\hline $\begin{array}{l}\text { Tabagismo } \\
\text { Nunca } \\
\text { Anterior } \\
\text { Atual } \\
\text { IAM prévio } \\
\text { Insuficiência Cardíaca }\end{array}$ & $\begin{array}{l}46(16,3) \\
111(39,4) \\
124(44) \\
60(21,3) \\
66(23,4) \\
\end{array}$ \\
\hline $\begin{array}{l}\text { Risco Cardíaco (American College of Physicians) } \\
\text { Baixo } \\
\text { Intermediário } \\
\text { Alto }\end{array}$ & $\begin{array}{l}122(43,3) \\
146(51,8) \\
14(5)\end{array}$ \\
\hline $\begin{array}{l}\text { Medicações } \\
\text { Betabloqueador } \\
\text { Estatina } \\
\text { IECA ou BRA } \\
\text { Aspirina }\end{array}$ & $\begin{array}{l}213(75,5) \\
279(98,9) \\
174(61,7) \\
251(89) \\
\end{array}$ \\
\hline $\begin{array}{l}\text { Parâmetros laboratoriais } \\
\text { Plaquetas } \times 10^{3} / \mathrm{mL} \\
\text { Hemoglobina, } \mathrm{g} / \mathrm{dL} \\
\text { LDL-colesterol, } \mathrm{mg} / \mathrm{dL} \\
\text { Creatinina de base, } \mathrm{mg} / \mathrm{dL}\end{array}$ & $\begin{array}{l}230,3 \pm 77,2 \\
13,5 \pm 1,6 \\
100,9 \pm 38,1 \\
1,13 \pm 0,4\end{array}$ \\
\hline $\begin{array}{l}\text { Cirurgia Vascular } \\
\quad \text { Procedimento Endovascular } \\
\text { Procedimento Convencional }\end{array}$ & $\begin{array}{l}125(44,3) \\
157(55,7)\end{array}$ \\
\hline $\begin{array}{l}\text { Doença Vascular } \\
\text { Doença Arterial Obstrutiva Periférica (DAOP) } \\
\text { Doença da Carótida } \\
\text { Aneurisma da Aorta Abdominal } \\
\text { Dissecção e Aneurisma da Aorta Torácica } \\
\text { Descendente } \\
\end{array}$ & $\begin{array}{l}82(29,1) \\
44(15,6) \\
116(41,1) \\
11(3,9)\end{array}$ \\
\hline
\end{tabular}

Nota: Variáveis categóricas expressas em número absoluto e percentagem. Variáveis contínua expressas em média e desvio padrão; IECA, Inibidor da Enzima Conversora da Angiotensina; BRA, Bloqueador do Receptor da Angiotensina.

\section{1- AVALIAÇÃO DOS OBJETIVOS}

\subsubsection{Avaliar a associação entre a presença de comorbidades com a incidência de IRA:}

Dos 282 pacientes incluídos, 102 (36,2\%) evoluíram com IRA pelos critérios do KDIGO nos primeiros 07 dias após a cirurgia, sendo que a maioria, $68(66,6 \%)$ foi classificada como KDIGO 1, 14 (13,7\%) KDIGO 2 e 20 (19,6\%) KDIGO 3. Entre os 34 pacientes classificados inicialmente como KDIGO 2 ou 3, 18 (52,9\%) necessitaram de terapia de substituição renal. 
Não houve diferença estatisticamente significativa entre os pacientes classificados com IRA ou não, quanto à distribuição por sexo, idade, prevalência de diabetes mellitus (DM), hipertensão arterial sistêmica, classificação de risco cardiovascular pelo American Cardiology perioperative guidelines (ACP) ou pelo uso de medicações. Também não foi encontrada diferença quando a IRA foi classificada de acordo com a gravidade (Tabelas 4 e 5):

Tabela 4 - Características clínicas dos pacientes conforme sua classificação em Injúria Renal Aguda

\begin{tabular}{|c|c|c|c|c|}
\hline Variáveis & $\begin{array}{l}\text { Total } \\
(n=282)\end{array}$ & $\begin{array}{l}\text { Com IRA } \\
(n=102)\end{array}$ & $\begin{array}{l}\text { Sem IRA } \\
(n=180)\end{array}$ & $p$ \\
\hline Sexo masculino & $203(72)$ & $71(69)$ & $132(73)$ & 0,5 \\
\hline Idade, anos & $66,7 \pm 9,6$ & $68 \pm 9,5$ & $66,0 \pm 9,6$ & 0,09 \\
\hline DM & $200(\overline{7} 0,9)$ & $21(20,5)$ & $46(25,5)$ & 0,34 \\
\hline HAS & $250(88,7)$ & $93(91,1)$ & $157(87,2)$ & 0,31 \\
\hline Dislipidemia & $200(70,9)$ & $74(72,5)$ & $126(70)$ & 0,56 \\
\hline $\begin{array}{l}\text { Tabagismo } \\
\text { Nunca } \\
\text { Atual } \\
\text { Anterior }\end{array}$ & $\begin{array}{l}46(16,3) \\
124(44) \\
111(39,4)\end{array}$ & $\begin{array}{l}22(21,5) \\
37(36,2) \\
42(41,1)\end{array}$ & $\begin{array}{l}24(13,3) \\
87(48,3) \\
69(38,3)\end{array}$ & 0.08 \\
\hline $\begin{array}{l}\text { ACP } \\
\text { Baixo } \\
\text { Intermediário } \\
\text { Alto }\end{array}$ & $\begin{array}{l}122(43,3) \\
146(51,8) \\
14(5)\end{array}$ & $\begin{array}{l}42(41,1) \\
54(52,9) \\
5(5)\end{array}$ & $\begin{array}{l}80(44,4) \\
92(51,1) \\
8(4,4)\end{array}$ & 0,78 \\
\hline $\begin{array}{l}\text { Patologia Vascular } \\
\text { Aneurisma de Aorta } \\
\text { Doença Vascular Periférica } \\
\text { Carótida }\end{array}$ & $\begin{array}{l}127(45) \\
82(29) \\
44(15,6)\end{array}$ & $\begin{array}{l}53(51,9) \\
27(26,4) \\
13(12,7)\end{array}$ & $\begin{array}{l}74(41,1) \\
55(50,9) \\
31(17,2)\end{array}$ & 0,125 \\
\hline
\end{tabular}

Nota: Variáveis categóricas expressas em número absoluto e percentagem. Variáveis contínuas expressas em média e desvio padrão; DM, Diabetes Mellitus; HAS, Hipertensão Arterial Sistêmica; ACP, Classificação do American College of Physicians.

Tabela 5 - Características clínicas dos pacientes conforme a gravidade da Injúria Renal Aguda pelo KDIGO

\begin{tabular}{|l|c|c|c|c|c|}
\hline & $\begin{array}{c}\text { KDIGO 0 } \\
(\mathbf{n = 1 8 0})\end{array}$ & $\begin{array}{c}\text { KDIGO 1 } \\
(\mathbf{n = 6 8}\end{array}$ & $\begin{array}{c}\text { KDIGO 2 } \\
(\mathbf{n}=\mathbf{1 4})\end{array}$ & $\begin{array}{c}\text { KDIGO 3 } \\
(\mathbf{n}=\mathbf{2 0})\end{array}$ & $\mathbf{p}$ \\
\hline Sexo masculino & $132(73,3)$ & $51(75)$ & $7(50)$ & $13(65)$ & 0,23 \\
\hline HAS & $157(87,2)$ & $64(94)$ & $11(78)$ & $18(90)$ & 0,2 \\
\hline DM & $46(25,6)$ & $12(17,6)$ & $4(28,6)$ & $5(25)$ & 0,5 \\
\hline DLP & $126(70)$ & $50(74,6)$ & $11(78,6)$ & $13(65)$ & 0,74 \\
\hline ACP & & & & & 0,8 \\
Baixo & 80 & 27 & 4 & 11 & \\
Intermediário & 92 & 37 & 9 & 8 & \\
Alto & 8 & 4 & 1 & 1 & \\
\hline Medicações & & & & & \\
IECA/BRA & $110(61)$ & $48(70,5)$ & $7(50)$ & $9(45)$ & 0,14 \\
Betabloqueador & $138(76)$ & $52(76)$ & $10(71)$ & $13(65)$ & 0,68 \\
AAS & $155(86)$ & $64(94)$ & $13(92,8)$ & $19(95)$ & 0,23 \\
Estatina & $179(99,4)$ & $67(98,5)$ & $14(100)$ & $19(95)$ & 0,30 \\
\hline
\end{tabular}

Nota: Variáveis categóricas expressas em número absoluto e percentagem. DM, Diabetes Mellitus; HAS, Hipertensão Arterial Sistêmica; ACP, Classificação do American College of Physicians. 
Quanto aos exames sanguíneos colhidos no pré-operatório, não observamos diferença estatisticamente significativa entre os valores de Hemoglobina, Plaquetas, Glicemia de jejum e níveis de colesterol, mas houve diferença nos valores de PCR e Creatinina de base (Tabela 6):

Tabela 6 - Características laboratoriais dos pacientes conforme sua classificação da Injúria Renal Aguda

\begin{tabular}{|c|c|c|c|c|c|}
\hline & $\begin{array}{l}\text { KDIGO } 0 \\
(n=180)\end{array}$ & $\begin{array}{l}\text { KDIGO } 1 \\
(n=68)\end{array}$ & $\begin{array}{c}\text { KDIGO 2 } \\
(n=14)\end{array}$ & $\begin{array}{l}\text { KDIGO } 3 \\
(n=20)\end{array}$ & $\mathbf{p}$ \\
\hline $\mathrm{Hb} m g / d L$ & $13,6 \pm 1,6$ & $13,3 \pm 1,6$ & $13,1 \pm 1,7$ & $13,6 \pm 1,7$ & ,41 \\
\hline Plaquetas (x1000) & $230,2 \pm 75,5$ & $225,9 \pm 72,3$ & $268 \pm 123,2$ & $219,8 \pm 66$ & ,271 \\
\hline PCR & $\begin{array}{c}11,2 \pm 25,2 \\
(n=136)\end{array}$ & $\begin{array}{c}14,6 \pm 23,1 \\
(n=47)\end{array}$ & $\begin{array}{c}41,6 \pm 57,1 \\
(n=9)\end{array}$ & $\begin{array}{c}12,9 \pm 10,2 \\
(n=14)\end{array}$ & 011 \\
\hline Glicemia $m g / d L$ & $\begin{array}{c}112,4 \pm 50,8 \\
(n=175)\end{array}$ & $\begin{array}{c}105,8 \pm 50,9 \\
(n=67)\end{array}$ & $\begin{array}{l}102 \pm 24 \\
(n=14)\end{array}$ & $\begin{array}{c}129,8 \pm 66,5 \\
(\mathrm{n}=18)\end{array}$ & ,301 \\
\hline CT $m g / d L$ & $\begin{array}{c}176,1 \pm 50,8 \\
(n=170)\end{array}$ & $\begin{array}{c}172,8 \pm 50,8 \\
(n=67)\end{array}$ & $\begin{array}{c}177,1 \pm 46,7 \\
(n=13)\end{array}$ & $\begin{array}{c}177,0 \pm 57,9 \\
(n=19)\end{array}$ &, 97 \\
\hline $\mathrm{LDL} m g / d L$ & $\begin{array}{c}100,2 \pm 35 \\
(n=168)\end{array}$ & $\begin{array}{c}100,5 \pm 44,3 \\
(n=65)\end{array}$ & $\begin{array}{c}108,4 \pm 34,5 \\
(n=13)\end{array}$ & $\begin{array}{c}103,8 \pm 46,2 \\
(n=19)\end{array}$ & ,879 \\
\hline Cr de base $m g / d L$ & $1,07+0,39$ & $1,28 \pm 0,4$ & $0,97 \pm 0,35$ & $1,24 \pm 0,6$ & ,001 \\
\hline
\end{tabular}

Nota: Variáveis contínuas expressas em média e desvio padrão; Hb, Hemoglobina; PCR,

Proteína C Reativa; CT, Colesterol Total; LDL, Low Density Lipoprotein; Cr, Creatinina.

\subsection{2 - Avaliar a associação entre o tipo de cirurgia vascular e fatores perioperatórios com o desenvolvimento de IRA:}

Quando avaliamos a relação entre o tipo de cirurgia vascular, variáveis do perioperatório e a Injúria Renal Aguda, observamos que há forte associação entre a gravidade da IRA com a necessidade de Hemotransfusão no transoperatório, uso do Cell Saver, duração da anestesia e Instabilidade hemodinâmica, definida como a necessidade de início de vasopressores durante a cirurgia. No entanto, não houve associação entre a gravidade da IRA com o tipo de procedimento (tradicional aberto ou endovascular), nem em relação ao tempo de duração da cirurgia. (Tabela 7). 
Tabela 7 - Tipo de cirurgia, variáveis do intraoperatório e a classificação de Injúria Renal Aguda

\begin{tabular}{|l|c|c|c|c|c|}
\hline & $\begin{array}{c}\text { KDIGO 0 } \\
(\mathbf{n = 1 8 0 )}\end{array}$ & $\begin{array}{c}\text { KDIGO 1 } \\
(\mathbf{n = 6 8 )}\end{array}$ & $\begin{array}{c}\text { KDIGO 2 } \\
(\mathbf{n = 1 4 )}\end{array}$ & $\begin{array}{c}\text { KDIGO 3 } \\
(\mathbf{n = 2 0 )}\end{array}$ & $\boldsymbol{p}$ \\
\hline $\begin{array}{l}\text { Instabilidade } \\
\text { Hemodinâmica }\end{array}$ & $36(20)$ & $23(33,8)$ & $8(57)$ & $15(75))$ & $<0,001$ \\
\hline $\begin{array}{l}\text { Cirurgia aberta } \\
\begin{array}{l}\text { Procedimento } \\
\text { endovascular }\end{array}\end{array}$ & $\begin{array}{l}91(50,5) \\
89(49,5)\end{array}$ & $\begin{array}{c}42(61,7) \\
26(38,3)\end{array}$ & $\begin{array}{c}9(64) \\
5(36)\end{array}$ & $\begin{array}{c}15(75) \\
5(25)\end{array}$ &, 094 \\
\hline $\begin{array}{l}\text { Duração da } \\
\text { cirurgia (min.) }\end{array}$ & $228(119)$ & $248(144)$ & $301(163)$ & $320(123)$ &, 061 \\
\hline $\begin{array}{l}\text { Duração da } \\
\text { anestesia (min.) }\end{array}$ & $318(135)$ & $354(151)$ & $379(190)$ & $478(175)$ & $<0,001$ \\
\hline $\begin{array}{l}\text { Hemotransfusão } \\
\text { na cirurgia }\end{array}$ & $41(22,7)$ & $21(30,8)$ & $7(50)$ & $15(75)$ & $<0,001$ \\
\hline Cell saver & $17(9,4)$ & $10(14,7)$ & $2(14,2)$ & $8(40)$ & 0,01 \\
\hline
\end{tabular}

Nota: Variáveis categóricas expressas em número absoluto e percentagem; min, minutos.

\subsection{3 - Avaliar se o marcador de função endotelial como a Dilatação Mediada por Fluxo (FMD) pode funcionar como preditor de risco para o desenvolvimento de Injúria Renal Aguda nos pacientes que serão submetidos a cirurgias vasculares:}

O FMD foi avaliado em 96 pacientes, sendo 1 eliminado por falta de dados da função renal no pós-operatório. Dos 95 pacientes, 19,1\% tinham um Clearance de Creatinina com base no MDRD maior que $90 \mathrm{ml} / \mathrm{min} / 1,73 \mathrm{~m}^{2}$. Os demais tinham critério para serem classificados pelo MDRD com Insuficiência Renal Crônica em estágio II (43,6\%) e em estágio III (37,2\%). A média do FMD da nossa amostra foi de 5,7\%. Não houve associação entre o FMD e os estágios de classificação de Clearance de Creatinina conforme o MDRD (Figura 2). 
Figura 2 - Relação entre o FMD e o Clearance de Creatinina conforme o MDRD

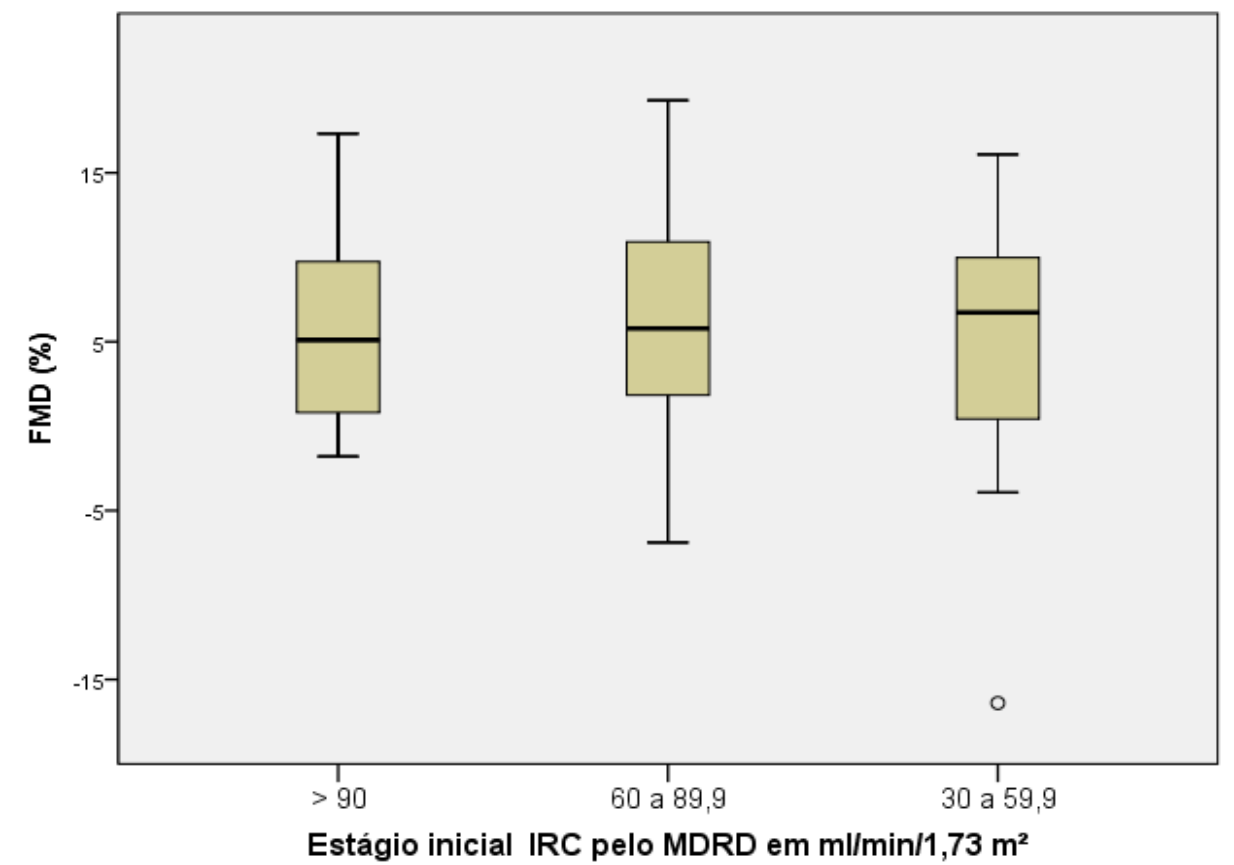

Nota: FMD, "Flow Mediated Dilation"; MDRD, "Modification of Diet in Renal Disease Study"

Não encontramos relação entre a presença de disfunção endotelial avaliada pelo FMD e a classificação de IRA pelo KDIGO $(p=0,66)$ Figura 3).

Figura 3 - Relação entre FMD e IRA conforme o KDIGO máximo atingido nos primeiros 7 dias de pós-operatório.

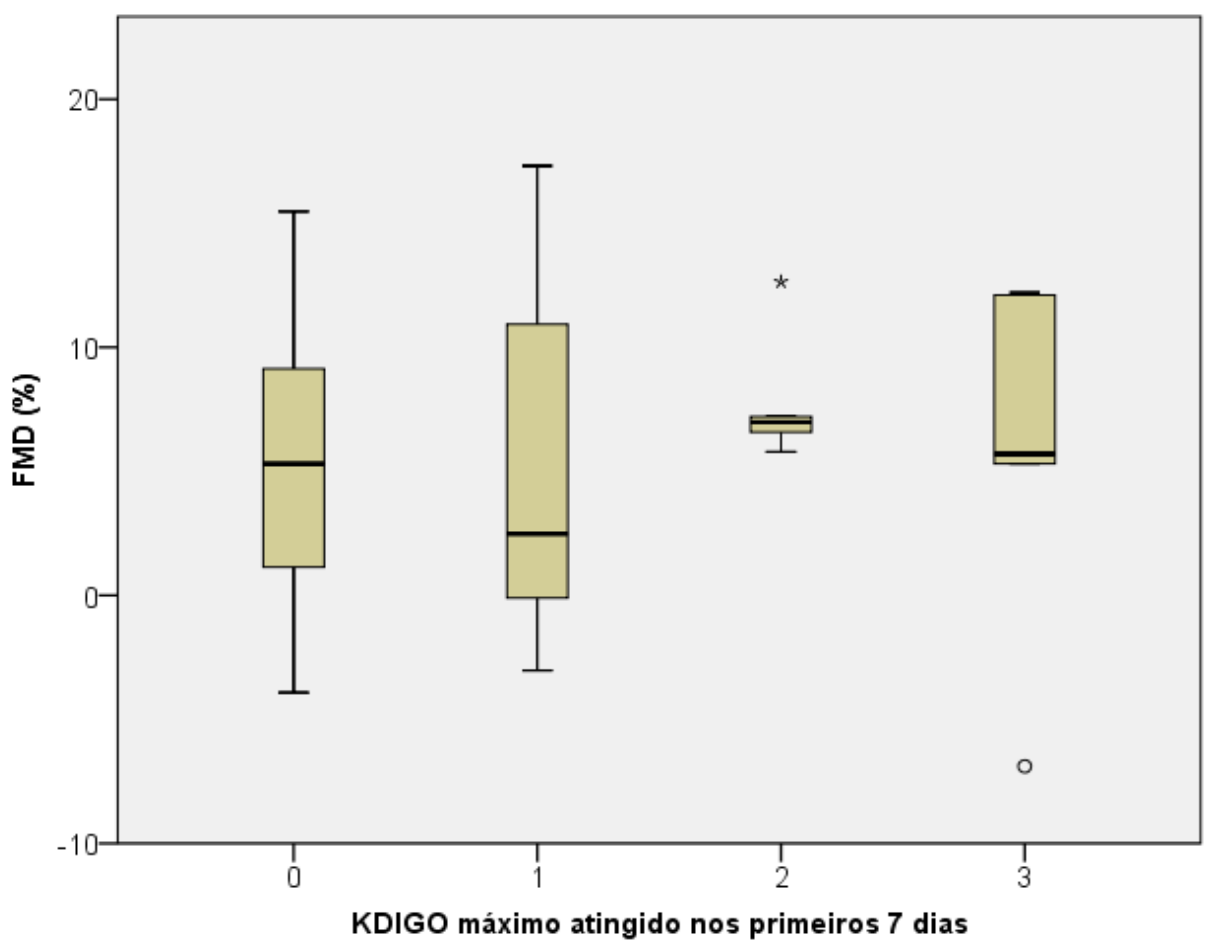

Nota: FMD, "Flow Mediated Dilation"; KDIGO, Kidney Disease Improving Global Outcome. 


\subsection{4 - Avaliar se a medida da agregabilidade plaquetária pode funcionar como} preditor de risco para o desenvolvimento de Injúria Renal Aguda nos pacientes que serão submetidos a cirurgias vasculares:

Ao avaliarmos todos os pacientes do estudo, encontramos uma diferença estatisticamente significante entre o número total de plaquetas e o Clearance de Creatinina pelo MDRD com $p=0,04$ (Figura 4):

Figura 4 - Relação entre o número de plaquetas e o Clearance de Creatinina conforme O MDRD

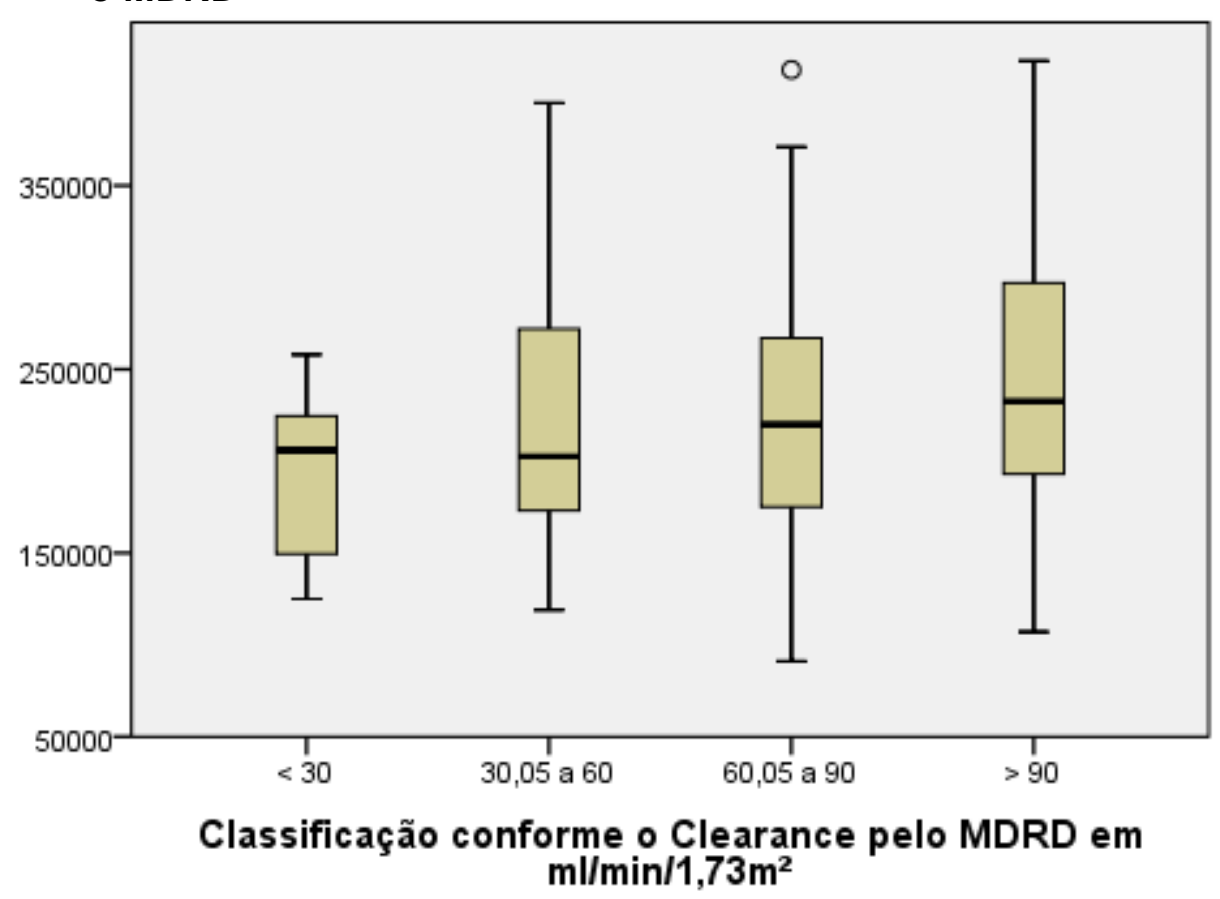

Nota: MDRD, "Modification of Diet in Renal Disease Study"

A agregabilidade dessas plaquetas foi avaliada em 187 pacientes. Encontramos uma associação significativa entre uma agregabilidade plaquetária maior, em resposta ao ácido araquidônico e o número total de plaquetas $p<0,001$ (Figura 5): 
Figura 5 - Relação entre a agregabilidade plaquetária expressa em Ohms após a administração do ácido araquidônico e a contagem total do número de plaquetas.

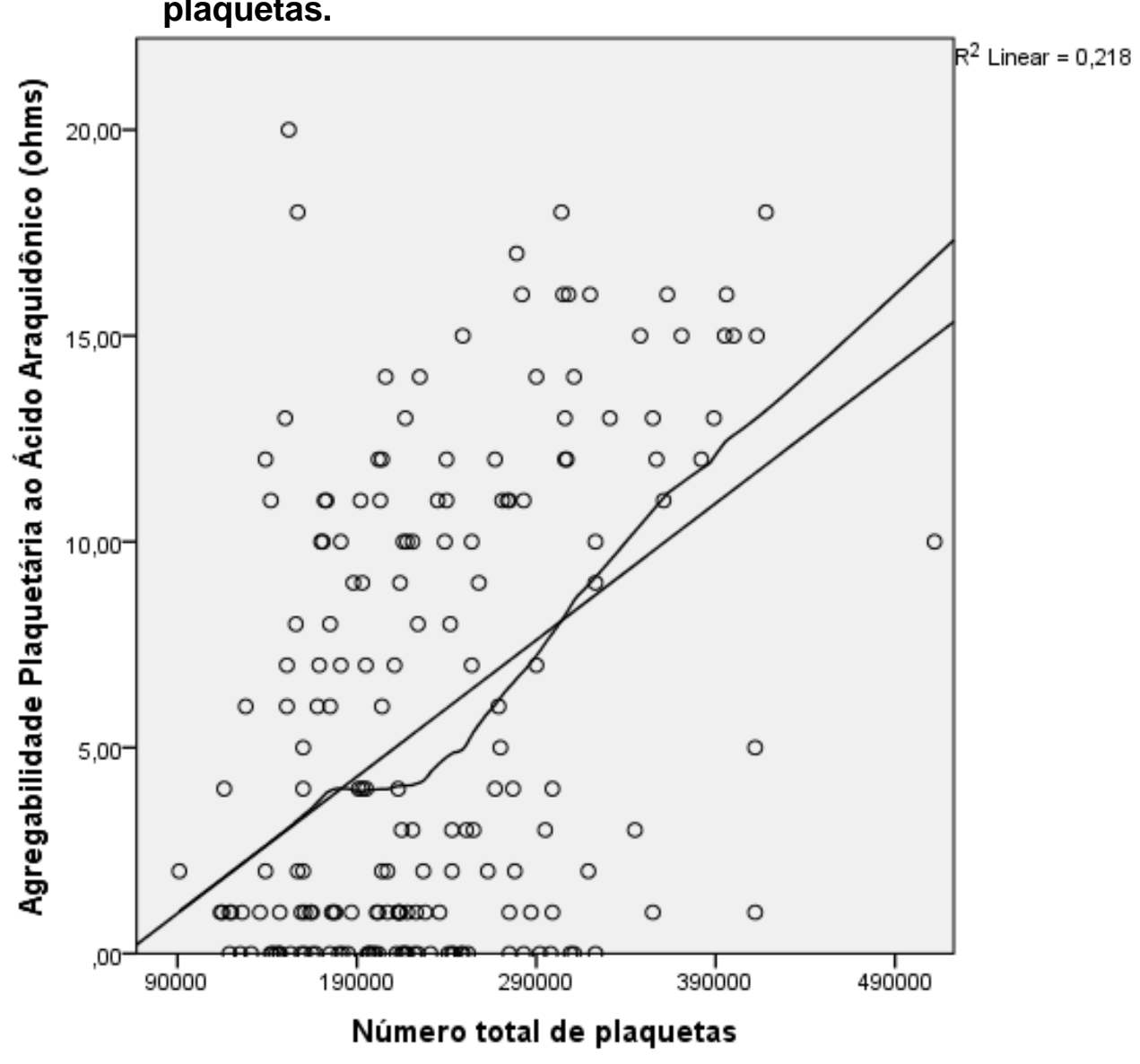

Nota: $\Omega$, ohms.

Avaliamos também a agregabilidade conforme os estágios de função renal pelo Clearance de Creatinina estimado pelo MDRD, mas não encontramos diferença $p=0,4$ (Tabela 8):

Tabela 8 - Agregabilidade plaquetária em Ohms após administração do ácido araquidônico e Estágios de função renal conforme o clearance de creatinina.

\begin{tabular}{|c|c|c|c|c|c|c|c|}
\hline & & \multicolumn{4}{|c|}{$\begin{array}{l}\text { Quartis de agregabilidade plaquetária expressa em } \\
\text { Ohms após a administração do ácido araquidônico }\end{array}$} & \multirow[b]{2}{*}{$\begin{array}{c}\text { Total } \\
(n=187)\end{array}$} & \multirow[b]{2}{*}{$p$} \\
\hline & & $\begin{array}{c}1^{\circ} \text { quartil } \\
(0 \text { a } 1 \Omega) \\
(n=76)\end{array}$ & $\begin{array}{c}2^{\circ} \text { quartil } \\
(1,1 \text { a } 4 \Omega) \\
(n=27)\end{array}$ & $\begin{array}{c}3^{\circ} \text { quartil } \\
(4,1 \text { a } 11 \Omega) \\
(n=46)\end{array}$ & $\begin{array}{c}4^{\circ} \text { quartil } \\
(>11 \Omega) \\
(n=38)\end{array}$ & & \\
\hline \multirow{4}{*}{$\begin{array}{l}\text { Estágios de } \\
\text { IRC } \\
\text { conforme o } \\
\text { Clearance } \\
\text { pelo MDRD }\end{array}$} & 1 & $1(16,7)$ & $1(16,7)$ & $2(33,3)$ & $2(33,3)$ & 6 & \multirow[t]{4}{*}{0,4} \\
\hline & 2 & $27(48,2)$ & $8(14,3)$ & $10(17,9)$ & $11(19,6)$ & 56 & \\
\hline & 3 & $35(39,5)$ & $15(17,4)$ & $24(27,9)$ & $13(15,1)$ & 86 & \\
\hline & 4 & $13(34,2)$ & $3(7,9)$ & $10(26,3)$ & $12(31,6)$ & 38 & \\
\hline
\end{tabular}

Nota: Variáveis categóricas expressas em número absoluto e percentagem 
Nos pacientes em que foi avaliada a agregabilidade plaquetária, encontramos uma associação entre a agregabilidade e a IRA, além de associação entre uma agregabilidade maior, com a gravidade da IRA, $p=0,04$ (Figura 6):

Figura 6 - Relação entre a agregabilidade plaquetária expressa em Ohms após a administração do ácido araquidônico e a gravidade da IRA conforme o KDIGO máximo atingido nos primeiros 7 dias de pós-operatório.

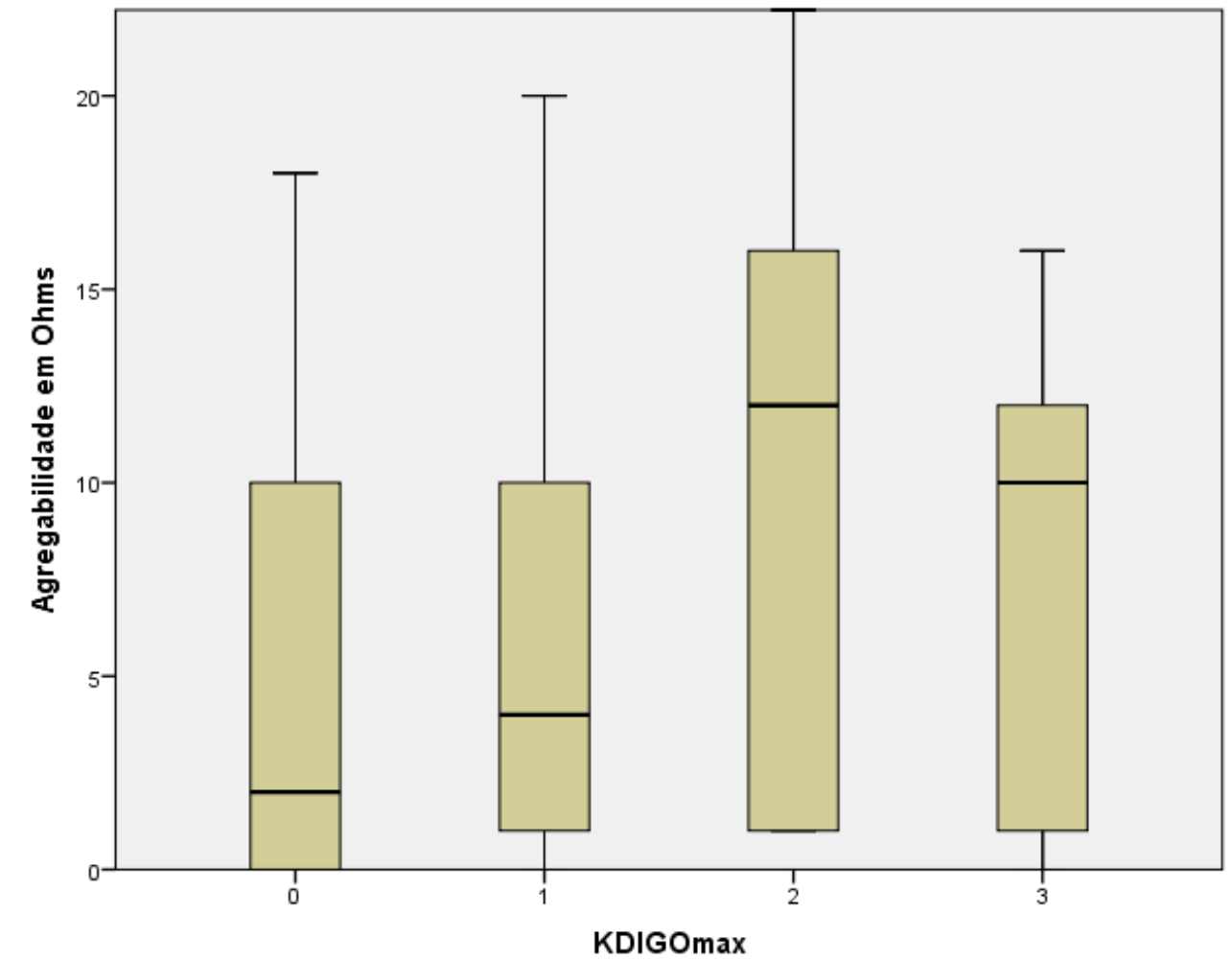

Nota: KDIGO, Kidney Disease Improving Global Outcome.

$\mathrm{Na}$ análise univariada dos pacientes em que coletamos a avaliação da agregabilidade plaquetária, alguns fatores foram relacionados com a Injúria Renal Aguda como o clearance de creatinina pelo MDRD calculado pela creatinina basal (média de 76,1 $\mathrm{ml} / \mathrm{min}$ em pacientes sem IRA versus $67,1 \mathrm{ml} / \mathrm{min}$ nos pacientes com IRA, $p=0,02$ ), a agregabilidade plaquetária em resposta ao ácido araquidônico (média de $5 \Omega$ versus $6,9 \Omega, p=0,03)$, instabilidade hemodinâmica no intraoperatório $(20 \%$ versus 47\%, p <0,001), duração da anestesia (média de 304,7 minutos versus 372,9, $p=0,003)$, transfusão sanguínea no intraoperatório (13,6\% versus $38,3 \%, p=0,002)$, o uso de Cell Saver (14,5\% versus $28,5 \%, p=0,02)$ e a ocorrência de evento cardiovascular $(15,3 \%$ versus $34,2 \%, p=0,003)$. 
Os preditores independentes de Injúria Renal Aguda foram instabilidade hemodinâmica, evento cardiovascular, menor clearance de creatinina e uma maior agregabilidade plaquetária.

Tabela 9 - Resultado da análise multivariada dos fatores preditores independentes para desenvolvimento de Injúria Renal Aguda.

\begin{tabular}{|l|l|l|l|l|}
\hline Variável & Categoria & OR & $\mathbf{9 5 \%}$ IC & p \\
\hline Instabilidade hemodinâmica & Não & 1 & Ref. & 0,012 \\
& Sim & 2,6 & $1,2-5,5$ & \\
\hline Evento cardiovascular & Não & 1 & Ref & 0,041 \\
& Sim & 2,31 & $1,0-5,1$ & \\
\hline TFG estimada (MDRD) & $>60 \mathrm{ml} / \mathrm{min} / 1.73 \mathrm{~m}^{2}$ & 1 & Ref & $<0,001$ \\
\hline Agregabilidade plaquetária $(\Omega)$ & $<60 \mathrm{ml} / \mathrm{min} / 1.73 \mathrm{~m}^{2}$ & 0,21 & $0,1-0,4$ & \\
& $\leq 1$ & 1 & $\operatorname{Ref}$ & 0,014 \\
\hline & $>1$ & 2,49 & $1,1-5,2$ & \\
\hline
\end{tabular}

\subsection{5 - Analisar se os pacientes que desenvolveram IRA pelos critérios do KDIGO na primeira semana de pós-operatório evoluem ou estão associados com um aumento de eventos cardiovasculares e se houve relação temporal entre Injúria Renal Aguda e Evento Cardiovascular.}

Analisando os 102 casos de IRA, observamos que 38 (37,3\%) ocorreram no pósoperatório imediato. Outros 39 no primeiro dia de pós-operatório, 20 (19,6\%) no segundo dia, dois no terceiro, um no sexto e dois no sétimo dia de pós-operatório (Figura 7).

Figura 7 - Dia do primeiro diagnóstico de IRA

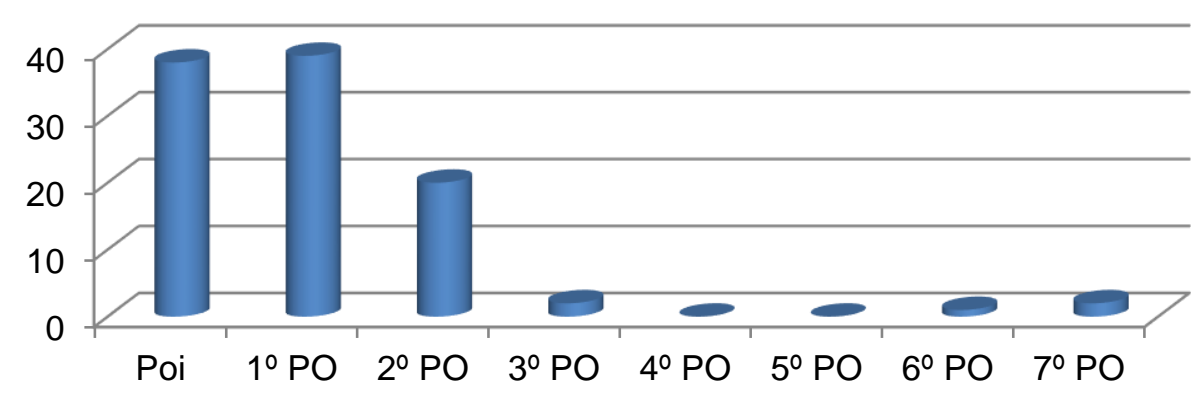

Nota: PO, pós-operatório; POi, pós-operatório imediato 
No total, foram 59 eventos cardiovasculares até o sétimo dia de pós-operatório $(20,9 \%)$, sendo 13 infartos, 2 anginas instáveis, 15 elevações isoladas de troponina, 11 Acidentes Vasculares Cerebrais isquêmicos, 14 reoperações e 4 mortes cardiovasculares (Figura 8).

\section{Figura 8 - Classificação dos Eventos cardiovasculares}
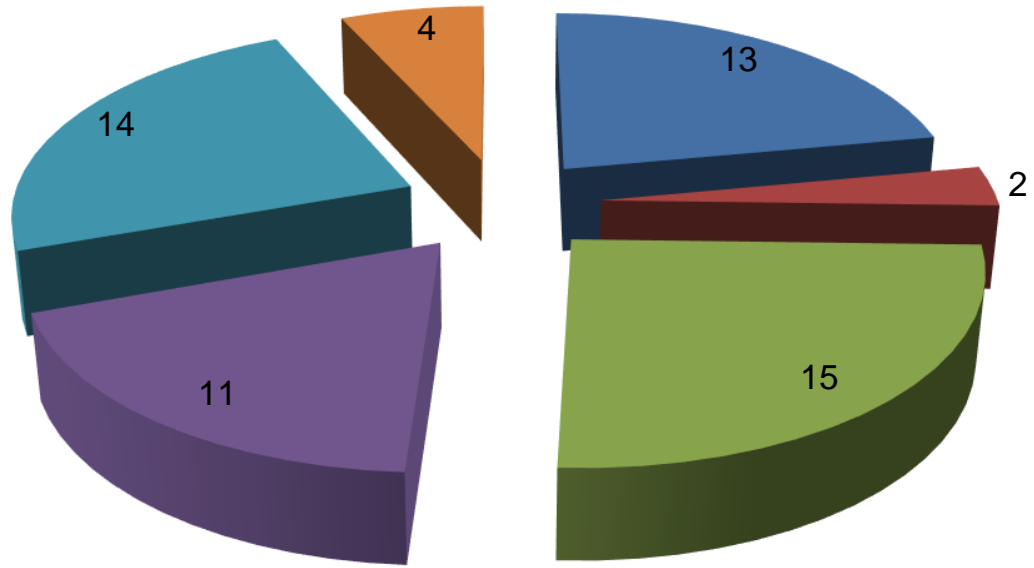

- IAM

- Angina Instável

Elevação de Troponina

AVCi

- Reoperação

- Morte Cardiovascular

Nota: IAM, Infarto Agudo do Miocárdio; AVCi, Acidente Vascular Cerebral Isquêmico

Assim como o diagnóstico de IRA, a incidência de Evento Cardiovascular foi maior nos primeiros dois dias de pós-operatório, sendo $16(27,1 \%)$ no pós-operatório imediato, 15 (25,4\%) no primeiro dia de pós-operatório e $14(23,7 \%)$ no segundo dia (Figura 9).

\section{Figura 9 - Dia do Evento Cardiovascular}

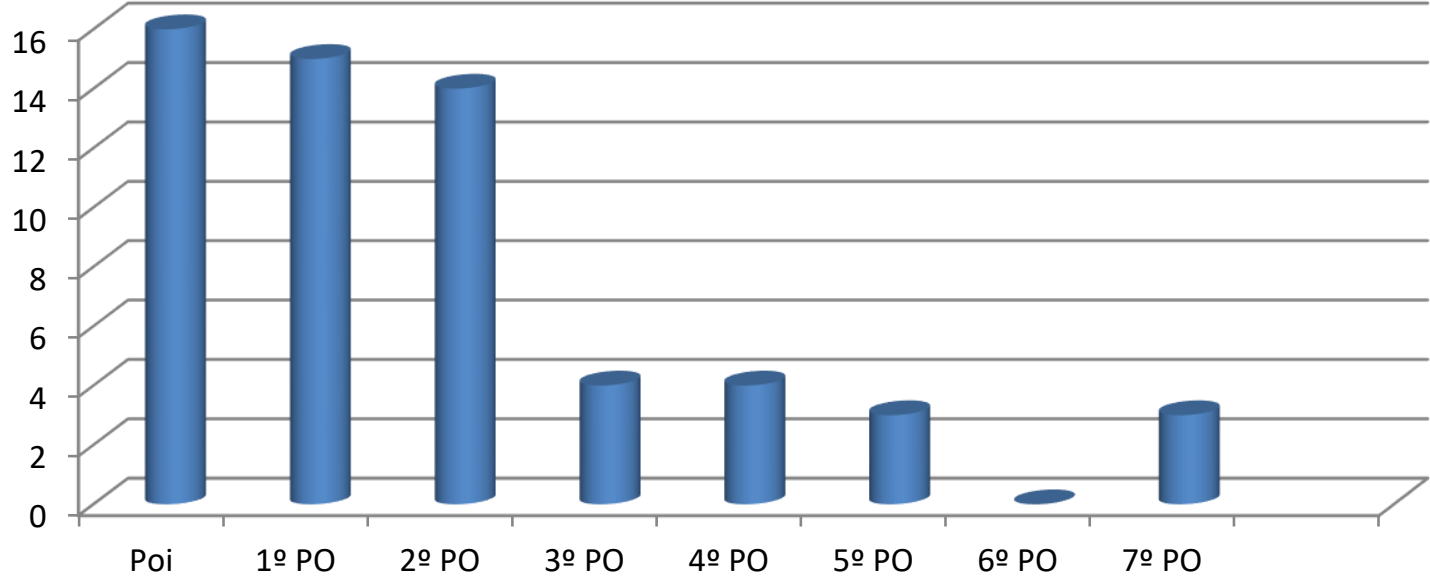

Nota: PO, Pós-operatório; POi, Pós-operatório imediato 
Ao analisarmos os grupos que desenvolveram IRA e Evento Cardiovascular, observamos que 27 (15\%) dos pacientes sem o diagnóstico de IRA tiveram Evento Cardiovascular e 32 (31,3\%) dos pacientes com o diagnóstico de IRA tiveram Evento Cardiovascular, $\mathrm{p}=0,002$ (Figura 10).

Figura 10 - - Relação entre o diagnóstico de IRA e Evento Cardiovascular

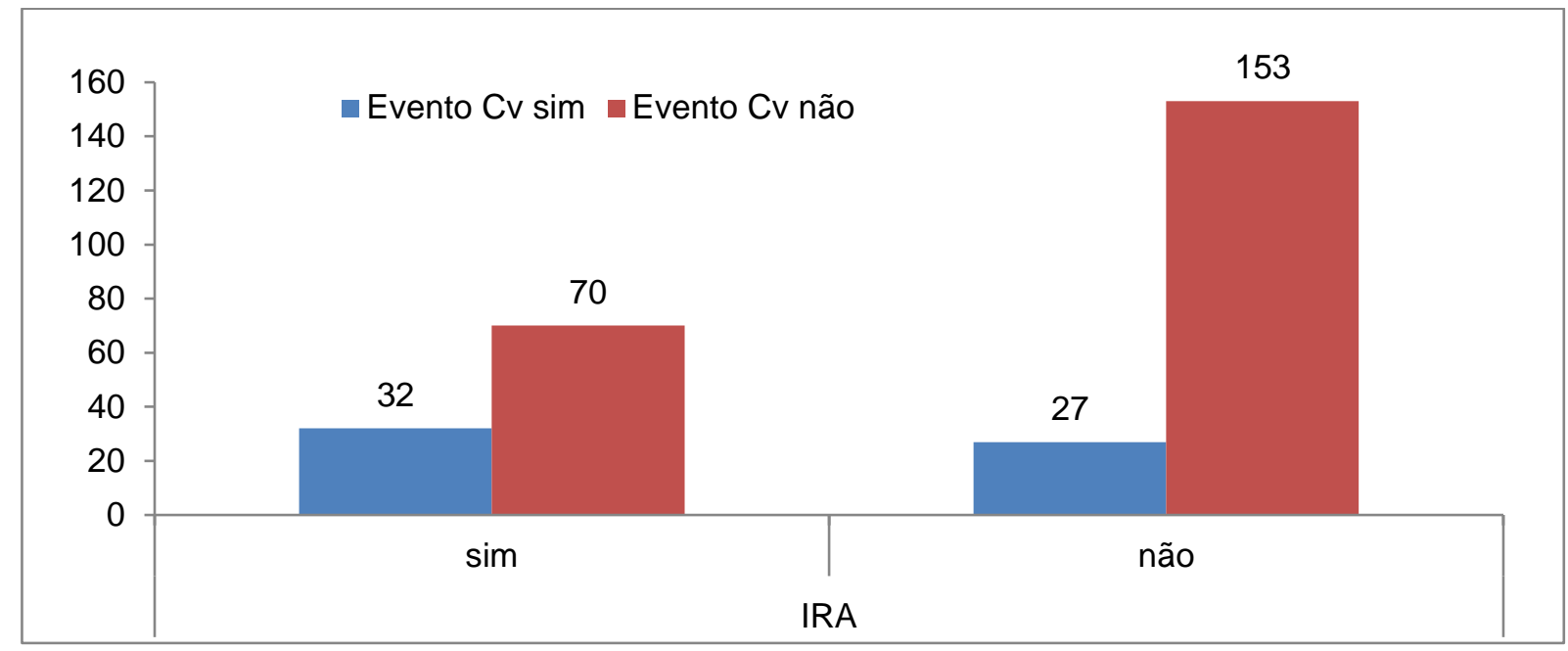

NOTA: IRA, Insuficiência Renal Aguda; Evento CV, Evento Cardiovascular

Ao classificarmos conforme a gravidade da IRA, notamos que há associação entre esta e uma maior incidência de Eventos Cardiovasculares. 22,0\% dos pacientes com o diagnóstico de KDIGO 1 desenvolveram evento cardiovascular; 42,8\% dos classificados como KDIGO 2 e 55\% dos classificados como KDIGO 3 ( $p<0,001$ ) (Figura 11).

Figura 11 - Relação entre a classificação de IRA e Evento Cardiovascular

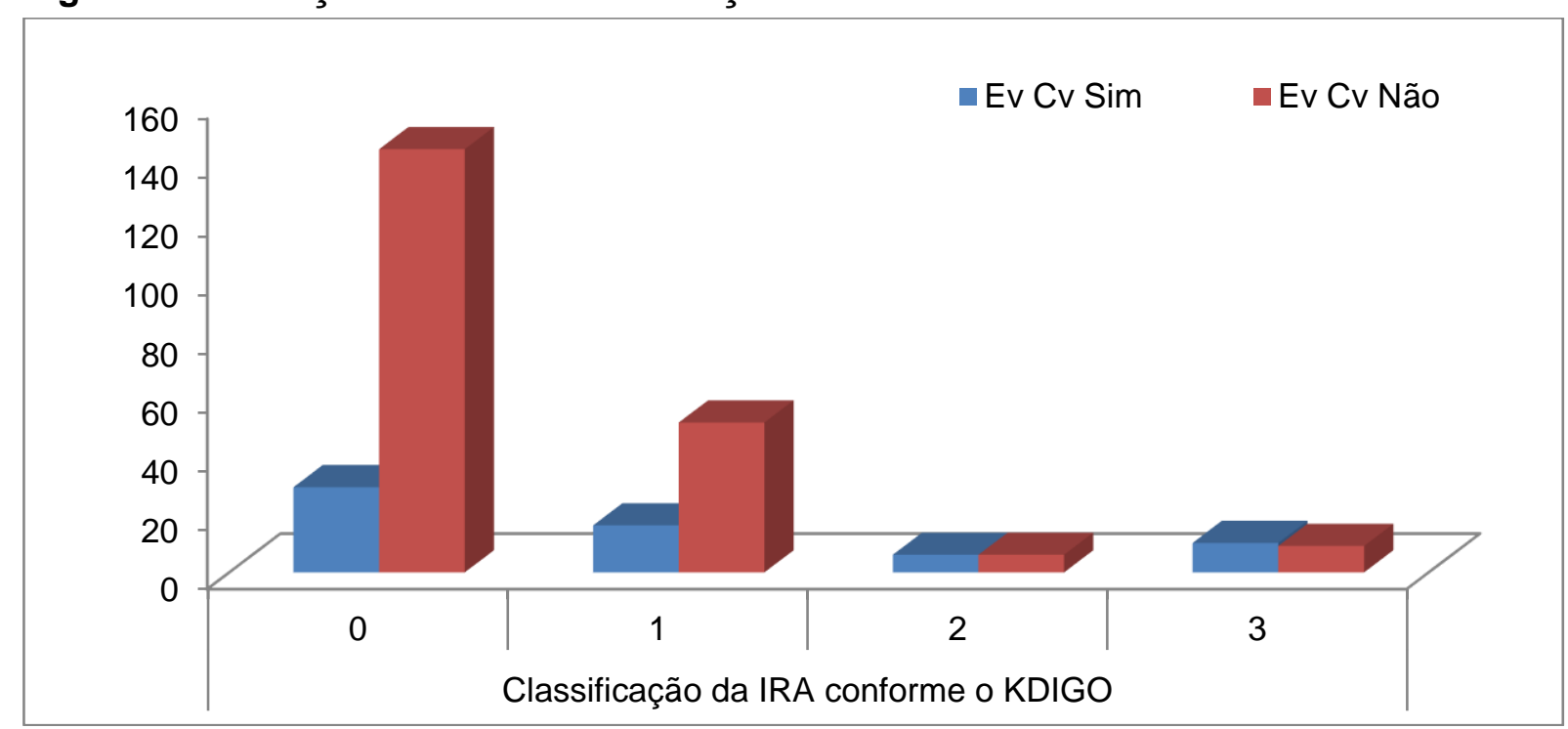

Nota: IRA, Insuficiência Renal Aguda; Evento CV, Evento Cardiovascular 
Avaliando apenas os 32 pacientes que desenvolveram IRA e Evento Cardiovascular nos primeiros 7 dias, notamos que a média de tempo para 0 diagnóstico de IRA foi 1,31 dias ( $D P \pm 1,63)$ e a média de tempo para o diagnóstico de Evento Cardiovascular foi de 2,13 dias ( $D P \pm 2,0$ ), com $p=0,089$, não sendo possível estabelecer uma relação temporal entre os dois eventos.

$\mathrm{Na}$ análise univariada (Tabela 10), os fatores relacionados com evento cardiovascular foram IRA, hemotransfusão, instabilidade hemodinâmica, duração da anestesia, valor do PCR e realização de hemodiálise. O único preditor independente de evento cardiovascular foi a necessidade de hemodiálise, $p<0,001$.

\begin{tabular}{|c|c|c|c|c|}
\hline & $\begin{array}{l}\text { Total } \\
\mathrm{n}=282\end{array}$ & $\begin{array}{l}\mathrm{EvCv} \\
\mathrm{n}=59\end{array}$ & $\begin{array}{l}\text { Não EvCv } \\
\mathrm{n}=223\end{array}$ & $\mathrm{p}$ \\
\hline IRA (\%) & $69,4(26,1)$ & $33(55,9)$ & $69(30,9)$ & 0,001 \\
\hline Hemotransfusão (\%) & $84(29,7)$ & $30(50,8)$ & $54(24,2)$ & $<0,001$ \\
\hline $\begin{array}{l}\text { Instabilidade hemodinâmica no } \\
\text { intraoperatório (\%) }\end{array}$ & $82(29)$ & $33(55,9)$ & $49(21,9)$ & $<0,001$ \\
\hline Duração da anestesia (min.) & $341(150,3)$ & $392(171,8)$ & $327(141,3)$ & 0,003 \\
\hline$P C R$ & $13,5(26,6)$ & $21,7(45,6)$ & $11,0(17,0)$ & 0,01 \\
\hline Hemodiálise & $18(6,3)$ & $11(18,6)$ & $7(3,1)$ & $<0,001$ \\
\hline
\end{tabular}

\subsection{6 - Avaliar se, nos pacientes submetidos a cirurgias vasculares, 0 diagnóstico e a gravidade da IRA estão associados a pior prognóstico, como maior tempo de internação e mortalidade.}

A média de tempo de internação na UTI no pós-operatório foi de $3,8( \pm 6,7)$ dias, sendo de 2,54 $( \pm 3,8)$ dias em pacientes sem IRA e 6,03 $( \pm 9,6)$ dias nos pacientes com IRA. Este tempo aumenta conforme a classificação da IRA pelo KDIGO. Uma diferença estatisticamente significante com $p<0,001$ (Figura 12). 
Figura 12 - Tempo médio de internação na UTI conforme classificação da IRA pelo KDIGO

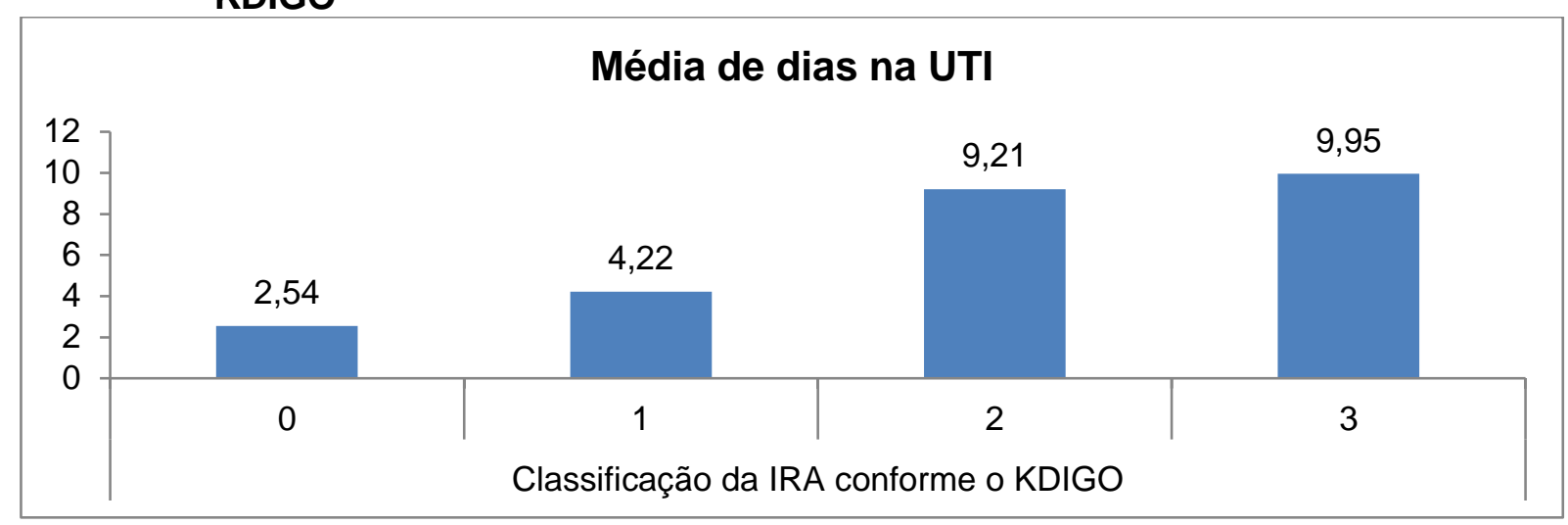

Nota: IRA, Insuficiência Renal Aguda; KDIGO, Kidney Disease Improving Global Outcome.

A mortalidade geral foi de 12,8\% (36 óbitos), sendo 12 (6,6\%) dos pacientes sem o diagnóstico de IRA e 24 (23,5\%) dos pacientes com diagnóstico de IRA. Uma diferença com $\mathrm{p}<0,001$.

Para avaliar a morbimortalidade que a IRA acrescenta a um evento cardiovascular, dividimos os pacientes em 4 grupos: 1 - pacientes sem evento cardiovascular e sem IRA ( $n=149) ; 2$ - pacientes com evento cardiovascular e sem IRA $(n=31) ; 3$ - pacientes com IRA e sem evento cardiovascular $(n=68)$ e 4 pacientes com IRA e com evento cardiovascular $(n=34)$. Não encontramos diferença nas características clínicas nem laboratoriais de base destes grupos, exceto pela classificação pelo MDRD com base na creatinina basal (Tabelas 11 e 12).

Tabela 11 - Características gerais dos pacientes conforme sua classificação da Injúria Renal Aguda e Evento Cardiovascular

\begin{tabular}{|l|c|c|c|c|c|}
\hline & $\begin{array}{c}\text { Grupo 1 } \\
(\mathbf{n = 1 4 9 )}\end{array}$ & $\begin{array}{c}\text { Grupo 2 } \\
(\mathbf{n = 3 1 )}\end{array}$ & $\begin{array}{c}\text { Grupo 3 } \\
\text { (n= 68) }\end{array}$ & $\begin{array}{c}\text { Grupo 4 } \\
(\mathbf{n = 3 4 )}\end{array}$ & p \\
\hline DM & $37(24,8)$ & $9(29)$ & $14(20,6)$ & $7(20,6)$ & 0,76 \\
\hline HAS & $126(84,6)$ & $31(100)$ & $63(92,6)$ & $30(88,2)$ & 0,06 \\
\hline Dislipidemia & $102(68,5)$ & $24(77,4)$ & $46(68,7)$ & $28(82,4)$ & 0,33 \\
\hline Risco Lee & & & & & 0,64 \\
1 & $9(6)$ & $1(3,2)$ & $1(1,5)$ & $1(3)$ & \\
2 & $64(43)$ & $10(32,2)$ & $33(48,5)$ & $17(50)$ & \\
3 & $53(35,6)$ & $15(48,3)$ & $24(35,3)$ & $9(26,5)$ & \\
4 & $23(15,4)$ & $5(16,1)$ & $10(14,7)$ & $7(20,6)$ & \\
\hline Cirurgia aberta & $73(49)$ & $18(58)$ & $45(66,2)$ & $21(61,8)$ & 0,097 \\
Procedimento & $76(51)$ & $13(42)$ & $23(33,8)$ & $13(38,2)$ & \\
endovascular & & & & & \\
\hline
\end{tabular}

Nota: Grupo 1, Sem IRA e sem Evento Cardiovascular; Grupo 2, Sem IRA e com Evento Cardiovascular; Grupo 3, Com IRA e sem Evento Cardiovascular; Grupo 4, Com IRA e com Evento Cardiovascular; DM, Diabetes Mellitus; HAS, Hipertensão Arterial Sistêmica. NOTA: Variáveis categóricas expressas em número absoluto e percentagem. 
Tabela 12 - Características laboratoriais dos pacientes conforme sua classificação da Injúria Renal Aguda e Evento Cardiovascular

\begin{tabular}{|l|l|l|l|l|l|}
\hline & $\begin{array}{l}\text { Grupo 1 } \\
(\boldsymbol{n}=\mathbf{1 4 9})\end{array}$ & $\begin{array}{l}\text { Grupo 2 } \\
(\boldsymbol{n}=\mathbf{3 1})\end{array}$ & $\begin{array}{l}\text { Grupo 3 } \\
(\boldsymbol{n}=\mathbf{6 8})\end{array}$ & $\begin{array}{l}\text { Grupo 4 } \\
(\boldsymbol{n}=\mathbf{3 4})\end{array}$ & $\boldsymbol{p}$ \\
\hline $\begin{array}{l}\text { MDRD com base na } \\
\text { Cr basal }\end{array}$ & $74,4(23,8)$ & $76,5(25)$ & $63,3(25,3)$ & $69,4(26,1)$ & 0,003 \\
\hline $\begin{array}{l}\text { Hemoglobina mg/dL } \\
\begin{array}{l}\text { Colesterol Total } \\
\text { mg/dL }\end{array}\end{array}$ & $13,7(1,5)$ & $13,3(1,9)$ & $13,3(1,6)$ & $13,5(1,7)$ & 0,35 \\
\hline Glicemia mg/dL & $177(53)$ & $170(39)$ & $170(44)$ & $183(63)$ & 0,88 \\
\hline PCR & $9,6(15,4)$ & $119(50)$ & $107(53)$ & $114(49)$ & 0,64 \\
\hline $\begin{array}{l}\text { Plaquetas } \\
\left(x 1000 / m^{3}\right)\end{array}$ & $229(74)$ & $234(80)$ & $223(73)$ & $244(91)$ & 0,68 \\
\hline
\end{tabular}

Nota: Grupo 1, Sem IRA e sem Evento Cardiovascular; Grupo 2, Sem IRA e com Evento Cardiovascular; Grupo 3, Com IRA e sem Evento Cardiovascular; Grupo 4, Com IRA e com Evento Cardiovascular. Variáveis contínuas expressas em média e desvio padrão

Observamos que houve uma diferença significativa no tempo de internação na UTI e na mortalidade geral entre os grupos, ambos com $p<0,001$ (Figuras 13 e 14).

Figura 13 - - Boxplot comparativo dos dias de internação na UTI.

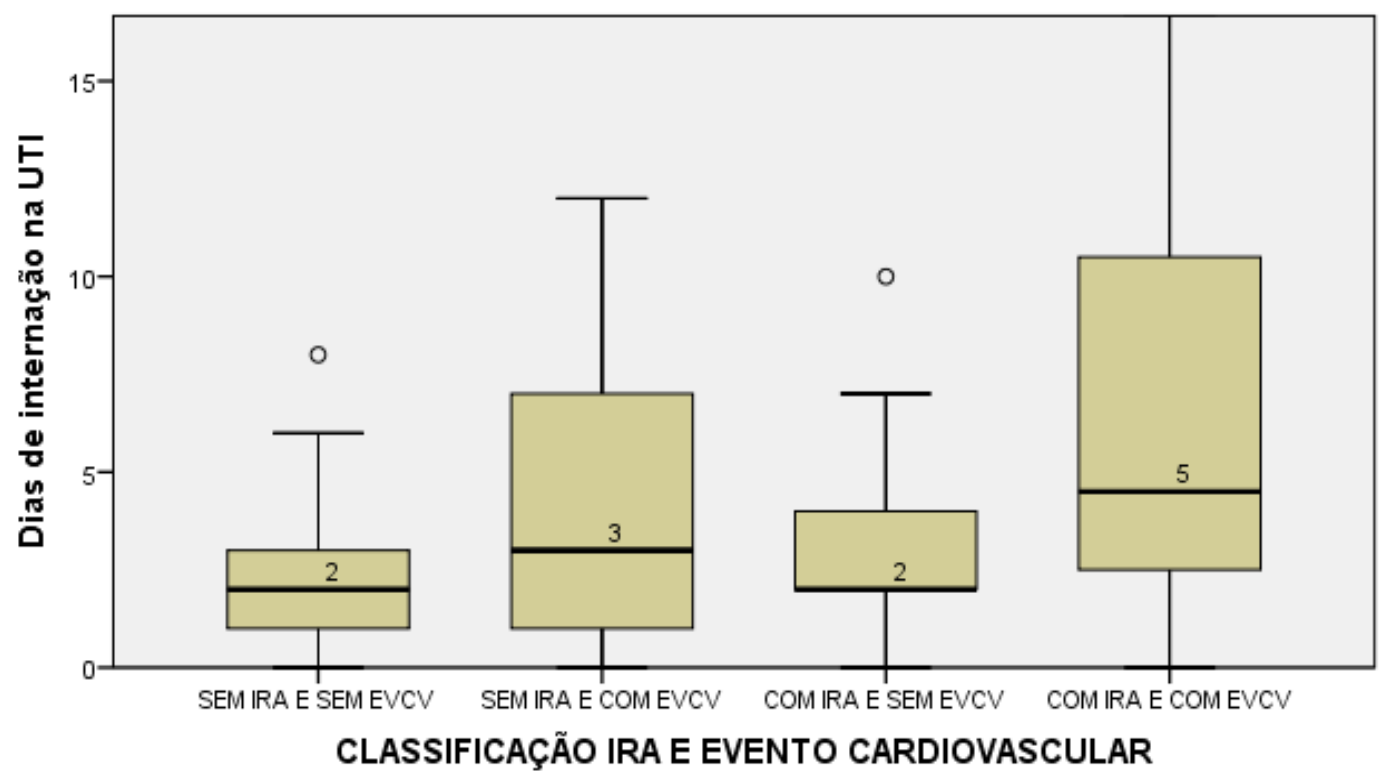

Nota: IRA, Injúria Renal Aguda, EVCV, Evento Cardiovascular. 
Figura 14 - Mortalidade geral de acordo com os grupos de gravidade.

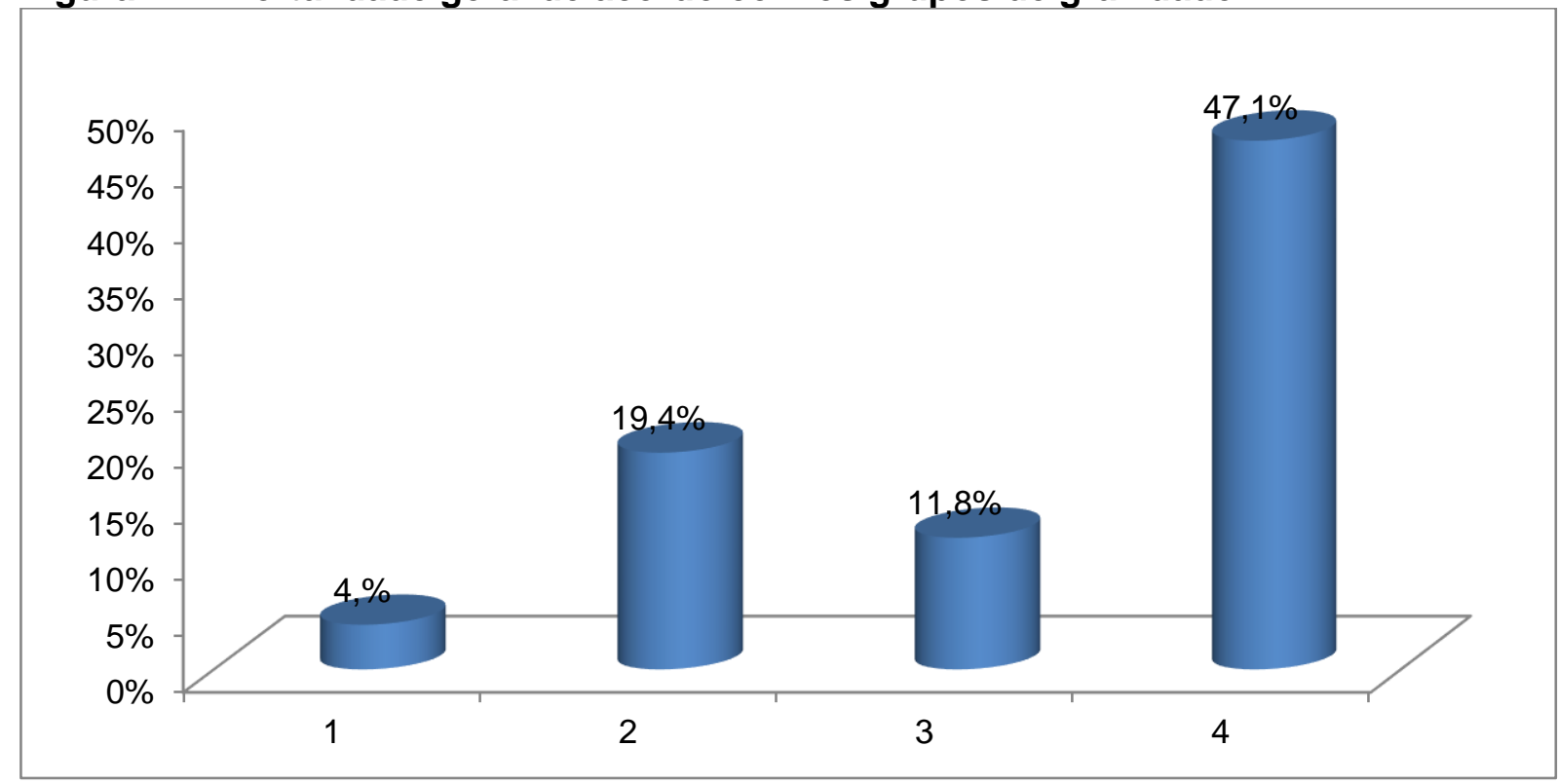

Nota: Grupo 1, Sem IRA e sem Evento Cardiovascular; Grupo 2, Sem IRA e com Evento

Cardiovascular; Grupo 3, Com IRA e sem Evento Cardiovascular; Grupo 4, Com IRA e com Evento Cardiovascular.

\subsection{7 - Recuperação da função renal}

Dos 102 casos de IRA, 24 foram a óbito. Dos demais 78, temos o acompanhamento da função renal, em médio prazo, de 41 pacientes (52,5\%). Destes, apenas $22(53,6 \%)$ apresentaram recuperação completa da função renal. 


\section{DISCUSSÃO}

\section{1 - A INJÚRIA RENAL AGUDA NAS CIRURGIAS VASCULARES}

A IRA é uma complicação comum de pacientes no perioperatório (35). Especificamente, os pacientes que serão submetidos a cirurgias vasculares têm em comum, fatores de risco conhecidos, para apresentarem disfunção renal como diabetes, hipertensão, tabagismo e insuficiência renal prévia, além de fatores relacionados à cirurgia como o uso do contraste iodado, a necessidade de clampeamento de aorta ou a possibilidade de embolização de placas ateromatosas. (36-40)

Neste estudo retrospectivo de avaliação de uma coorte prospectiva com 282 pacientes submetidos a grandes cirurgias vasculares eletivas, a Injúria Renal Aguda ocorreu em $102(36,2 \%)$ pacientes nos primeiros 7 dias de pós-operatório, sendo a maioria classificada como IRA leve, KDIGO 1 (66,6\%). Dezoito pacientes (6,3\%) necessitaram de Terapia de Substituição Renal. Kashani e colaboradores encontraram resultados compatíveis com os nossos, em população semelhante (41); no entanto, nós optamos por não incluir pacientes infectados ou cirurgias realizadas em caráter de emergência, para excluir outras causas de IRA que não fossem relacionadas ao evento cirúrgico. Não encontramos diferenças nas características clínicas e epidemiológicas entre os pacientes que desenvolveram e os que não desenvolveram IRA, exceto nos dados laboratoriais de PCR e Clearance de Creatinina calculado pelo MDRD. Alguns fatores perioperatórios foram relacionados com 0 desenvolvimento e gravidade da Injúria Renal como a necessidade de uso de vasopressores no intraoperatório, hemotransfusões, o uso de Cell Saver e o tempo de anestesia. Alguns destes fatores já foram relatados em outros estudos nesta população e podem estar relacionados a alguma dificuldade maior, na técnica operatória $(35,42)$. No entanto, não houve relação entre o tipo de cirurgia (aberta ou procedimento endovascular) nem com o tipo de patologia vascular e o subsequente desenvolvimento de IRA.

O diagnóstico de IRA foi feito em 95\% dos casos em até 48 horas do pósoperatório. Notamos que mesmo o diagnóstico de IRA leve (KDIGO 1) está associado a um pior prognóstico do paciente com maior tempo de internação em unidade 
fechada: $2,54( \pm 3,8)$ dias em pacientes sem o diagnóstico de IRA versus $4,22( \pm 8,4)$ dias nos pacientes com IRA KDIGO 1, $p=0,034$, compatível com revisão publicada em 2015 (35). Este tempo aumenta conforme a gravidade da IRA, assim como a mortalidade associada: $6,6 \%$ dos pacientes sem o diagnóstico de IRA e $23,5 \%$ dos pacientes com diagnóstico de IRA, $p<0,001$.

Harris e cols., em estudo publicado recentemente, tiveram uma incidência de IRA em cirurgias vasculares, mais elevada que a nossa (48\%) mas, em sua população, não foram excluídos os pacientes que entraram com necessidade de cirurgia de urgência nem os que foram admitidos com infecção, podendo tais características serem responsáveis pela maior incidência. Como em nosso estudo, este autor também teve maior número de diagnósticos no primeiro dia de pósoperatório e a Injúria classificada como mais leve foi a mais comum (60\%). Assim como em nosso trabalho, Harris e cols. também não encontraram diferença entre as patologias vasculares e a incidência de IRA (42).

\section{2 - DILATAÇÃO MEDIADA PELO FLUXO COMO PREDITOR DE INJÚRIA RENAL AGUDA}

A principal evidência de lesão renal que utilizamos, ainda é buscando alteração na função com consequente redução da filtração glomerular, seja manifestada na redução no fluxo urinário ou no aumento da creatinina. A teoria mais difundida ainda é que a redução da filtração glomerular seja um reflexo da redução da perfusão renal(43). No entanto, crescem as evidências de que a fisiopatologia da IRA envolve uma complexa interface entre fatores hemodinâmicos renais, processo inflamatório, lesão tubular e da célula endotelial. Após possível lesão isquêmica, a célula endotelial pode prolongar o tempo de isquemia, mesmo na fase de reperfusão, mostrando uma disfunção desta célula com a consequente piora ao dano às células tubulares (7). As alterações na função da célula endotelial provavelmente influenciam na vasodilatação, cascata da coagulação e no processo inflamatório(10). Uma das características da disfunção endotelial é a redução na capacidade de vasodilatação - o que é uma função atribuída ao Óxido Nítrico. As células endoteliais, particularmente as da medula renal, produzem óxido nítrico em grande quantidade como resposta a agentes estressores (44). 
Com base na teoria de que a IRA pode ter como fator etiológico uma disfunção da célula endotelial, este estudo propôs, pela primeira vez, que um exame utilizado para a avaliação da função endotelial seja utilizado como preditor da Injúria Renal Aguda.

Analisamos a Dilatação Mediada pelo Fluxo (FMD) de 95 pacientes. O FMD médio desta população foi de 5,7\%, bem abaixo de populações analisadas em outros trabalhos. Shechter e cols., em sua análise do FMD de pacientes saudáveis com o intuito de predizer eventos cardiovasculares a longo prazo, encontrou um FMD médio de $11,3 \%$ (45). Em sua descrição original em 1992, Celermajer e cols. obteve um FMD médio de 10\%, sendo menor em tabagistas e em dislipidêmicos(46). Trabalhos posteriores corroboraram este dado e também adicionaram outros fatores relacionados à menor dilatação mediada pelo fluxo, como eventos vasculares prévios, insuficiência renal crônica, idade e obesidade (47-50).

O baixo valor do FMD encontrado em nosso estudo talvez possa vir a ser explicado por tratar-se de pacientes já com doença vascular, muitos com disfunção renal prévia, sendo $81 \%$ com Clearance de Creatinina $\leq 60 \mathrm{ml} / \mathrm{min} / \mathrm{m}^{2} ; 95 \% \mathrm{com}$ hipertensão e $86 \%$ de tabagistas, comorbidades já sabidamente associadas com a redução do valor da dilatação mediada pelo fluxo. Talvez também por isso, não encontramos uma associação entre o FMD e os estágios de classificação de Clearance de Creatinina, ao contrário do que já observado por Thambyrajah e cols. (47) e mais recentemente por Tripolino e cols. (51).

\section{3 - AGREGABILIDADE PLAQUETÁRIA COMO PREDITOR DE INJÚRIA RENAL AGUDA}

Alguns estudos já demonstraram uma redução gradativa na contagem global de plaquetas com a perda da função renal (52). No entanto, são complexas as relações entre função renal e hemostasia. Pacientes com disfunção renal crônica têm uma tendência maior a eventos hemorrágicos que são principalmente devido a uma disfunção da hemostasia primária, aparentemente devido a um defeito na interação da plaqueta com as células endoteliais(53). Ao mesmo tempo, pacientes com disfunção renal também apresentam uma propensão maior a eventos trombóticos evidenciada, por exemplo, por maior incidência de infarto agudo do miocárdio e acidente cerebral isquêmico nessa população. 
Este estudo propõe, pela primeira vez, uma associação entre agregabilidade plaquetária e IRA, em pacientes submetidos a cirurgias vasculares, mesmo já fazendo uso de aspirina. Em pacientes cirúrgicos, a formação de trombos pode estar relacionada à perda de enxerto ou a eventos trombóticos. Na população estudada, a melhor resposta à aspirina evidenciada pela menor agregabilidade plaquetária foi associada à maior proteção contra IRA e contra eventos cardiovasculares.

Gremmel e cols.(54) demonstraram em seu trabalho uma maior atividade plaquetária em pacientes com insuficiência renal crônica, além de uma reduzida ação de inibição plaquetária nos pacientes renais crônicos que foram submetidos a angioplastia e faziam uso de aspirina e clopidogrel. Outros estudos já tinham demonstrado essa diferença na atividade plaquetária em pacientes com IRC e uma maior resistência ao efeito de antiagregantes plaquetários(55-57).

Em nosso estudo não conseguimos demonstrar uma diferença entre a agregabilidade e o Clearance de Creatinina estimado pelo MDRD, porém, os pacientes com maior agregabilidade, mesmo em uso de aspirina, tiveram maior propensão a desenvolver Injúria Renal Aguda. Notamos também, que houve associação entre a intensidade da reatividade plaquetária com a gravidade da IRA.

Analisando a agregabilidade com o ácido araquidônico como agonista, observamos que $19 \%$ dos pacientes no quarto quartil de agregabilidade tiveram IRA com classificação mais grave (KDIGO 2 e 3 ), ao passo que apenas $8,8 \%$ dos pacientes do primeiro ao terceiro quartil tiveram IRA mais grave, com $p=0,04$.

Avaliando os fatores que pontuaram para a nossa análise multivariada, notamos que o quarto quartil de agregabilidade (maior que 11 $\Omega$ ) foi o fator mais associado à IRA. Outras variáveis como o clearance de creatinina já é um fator classicamente ligado a eventos de Injúria Renal, o que pode estar relacionado a uma predisposição prévia destes pacientes(58). As demais variáveis estão relacionadas ao evento cirúrgico: instabilidade hemodinâmica no intraoperatório, a duração da anestesia, transfusão sanguínea e o uso do Cell Saver. Alguns autores já publicaram mostrando a associação entre hipotensão no intraopetatório e o desenvolvimento de $\operatorname{IRA}(59,60)$. Em uma coorte retrospectiva com pacientes cirúrgicos não cardíacos, Walsh et al. demonstraram que uma pressão arterial média (PAm) menor que 60 $\mathrm{mmHg}$ por mais de 20 minutos ou menor que $55 \mathrm{mmHg}$ por mais de 10 minutos foi associada diretamente com episódios de IRA(59). Metanálise anterior já propunha 
este cuidado com a manutenção dos níveis pressóricos em pacientes cirúrgicos com o intuito de preservar a função renal(61).

Embora o conceito fisiológico de que uma maior agregabilidade está diretamente relacionada a mais episódios de IRA seja fácil de entender, não encontramos trabalhos que mostrem essa associação. O grupo do POISE-2 publicou em 2014 um trial com o objetivo de avaliar se o uso da aspirina poderia prevenir os episódios de IRA em pacientes cirúrgicos. Os resultados deste grupo foram negativos quanto à proteção renal e os autores relatam em sua análise post hoc que possivelmente os resultados tenham ocorrido, em decorrência dos eventos hemorrágicos que aconteceram no grupo usando aspirina(62). No entanto, alguns trabalhos vêm demonstrando que, mesmo em uso de aspirina, muitos pacientes permanecem com a agregabilidade plaquetária elevada e permanecem tendo eventos trombóticos(63).

Embora não haja um valor que possa ser considerado "normal" para a agregabilidade, alguns autores consideram que, em uso de aspirina, o teste da agregabilidade com o ácido araquidônico deveria ser $0 \Omega$ e outros como menor que $3 \Omega(24)$. Em nosso trabalho, metade dos pacientes tiveram seus valores maiores que $4 \Omega$, mesmo em uso de aspirina. Importante ressaltar que, diferente do que poderíamos pensar, não encontramos uma diferença estatisticamente significante em eventos hemorrágicos nos pacientes com menor agregabilidade do primeiro quartil (49\%) versus o quarto quartil (52\%), $p=0,74$. Consideramos alta a nossa taxa de eventos hemorrágicos, mas também atribuímos ao conceito altamente sensível que utilizamos.

\section{4 - ASSOCIAÇÃO ENTRE INJÚRIA RENAL AGUDA E EVENTOS CARDIOVASCULARES}

Cirurgias vasculares são consideradas de alto risco para complicações cardiovasculares(64) e renais(42), mas há poucos estudos evidenciando a relação de ambos eventos nestes pacientes. Recentemente foi publicada uma coorte multicêntrica de pacientes submetidos a cirurgias vasculares com observação a longo prazo do prognóstico desses pacientes. Neste estudo, episódios de IRA no pósoperatório estavam associados a maior número de eventos cardiovasculares tardios em um tempo médio de observação de 62 meses (65). Em nossa coorte, tivemos 59 eventos cardiovasculares $(20,9 \%)$ e $102(36,1 \%)$ pacientes com injúria renal. Notamos 
que os eventos cardiovasculares e os episódios de IRA aconteceram principalmente no pós-operatório imediato e nas primeiras $48 \mathrm{~h}$. Pacientes com IRA tiveram mais que o dobro de eventos cardiovasculares (15\% versus $31,3 \%, p=0,002)$. Os eventos cardiovasculares também foram mais incidentes em pacientes com IRA mais grave pela classificação do KDIGO: $22 \%$ dos pacientes com KDIGO 1; 42,8\% dos classificados como KDIGO 2 e 55\% dos classificados como KDIGO 3 ( $p<0,001$ ). Não conseguimos estabelecer uma relação temporal para estimar se um evento precedeu o outro, pois avaliando os 32 pacientes que desenvolveram IRA e Evento Cardiovascular nos primeiros 7 dias, notamos que a média de tempo para 0 diagnóstico de IRA foi 1,31 dias (DP $\pm 1,63$ ) e a média de tempo para o diagnóstico de Evento Cardiovascular foi de 2,13 dias ( $D P \pm 2,0$ ), com $p=0,08$. Avaliamos este tempo diagnóstico com o intuito de tentar mostrar que algum evento poderia ter contribuído para o outro, como IRA predispondo a evento cardiovascular, ou o oposto, como é preconizado pela classificação da síndrome cardiorrenal tipos 1 e 3 . Admitimos em nosso trabalho uma falha na comparação dos diagnósticos já que definimos IRA como uma alteração da creatinina, sabidamente um marcador de função renal e não de lesão. Em contrapartida, para diagnóstico de evento cardiovascular, adotamos marcadores de lesão como a troponina ou o eletrocardiograma. No entanto, mesmo com essa falha, observamos uma tendência, não estatisticamente significativa, de que a IRA antecedia o evento cardiovascular. Observamos ainda que $27,1 \%$ dos diagnósticos de IRA foram feitos já na admissão do paciente em exames colhidos no pós-operatório imediato. Podemos pensar que seriam casos de uma síndrome cardiorrenal tipo 3 na qual temos uma IRA predispondo a um evento cardiovascular. Possivelmente, se tivéssemos utilizado marcadores de lesão renal, poderíamos demonstrar mais casos de IRA precedendo o evento cardiovascular. Entretanto, observando a fisiopatologia da síndrome coronariana e da injúria renal, preferimos pensar que temos pacientes com fatores que aumentam a predisposição aos dois eventos como uma disfunção endotelial e maior agregabilidade plaquetária. Desta forma, alguns destes pacientes têm maior predisposição a estes eventos, mesmo que marcadores clássicos como a idade, a presença de doenças como diabetes e hipertensão ou marcadores de gravidade como o APACHE, ACS e o risco Lee não tenham mostrado essa diferença. Continuamos com a dúvida se há uma relação causal entre os dois eventos ou se não passa de uma associação. 
Ao separarmos os pacientes em quatro grupos como: 1 - pacientes sem evento cardiovascular e sem IRA ( $n=149) ; 2$ - pacientes com evento cardiovascular e sem IRA ( $n=31)$; 3 - pacientes com IRA e sem evento cardiovascular $(n=68)$ e 4 pacientes com IRA e com evento cardiovascular $(n=34)$, tentamos avaliar o quanto de morbimortalidade que o evento IRA acrescentava no evento cardiovascular. Notemos que a mortalidade do grupo com IRA e EvCv (47,1\%) foi mais que dobro da mortalidade do grupo apenas com EvCv (19,4\%) e o quádruplo do grupo apenas com IRA (11,8\%). Harris et al. já demonstraram em seu trabalho um aumento de mortalidade a curto e longo prazo dos pacientes que desenvolveram IRA após cirurgias vasculares (42).

Em nosso trabalho, IRA e eventos cardiovasculares foram associados com alguns comuns fatores de risco como a instabilidade hemodinâmica. No entanto, na análise multivariada, o único fator independente de risco para evento cardiovascular foi o início da hemodiálise, confirmando a gravidade de IRA como o pior fator prognóstico.

Nosso trabalho tem algumas limitações. Primeiro, trata-se de uma coorte retrospectiva em um único hospital. Seu objetivo inicial não foi o de avaliar o evento IRA, mas sim o evento cardiovascular. Inicialmente pensamos em separar os diferentes tipos de cirurgias vasculares imaginando que alguns tipos poderiam ter incidência maior de IRA. No entanto, optamos por manter tais grupos em única análise por não termos encontrado diferença nos eventos IRA ou EvCv. Como observado anteriormente, não utilizamos outros métodos de detecção de lesão renal para o conceito de IRA, nem mesmo conseguimos dados confiáveis de diurese, o que provavelmente subestima o número total de IRA e superestima o tempo de diagnóstico. 


\section{CONCLUSÃo}

Este estudo fez uma análise retrospectiva de dados coletados prospectivamente, mostrando que a Injúria Renal Aguda e os Eventos Cardiovasculares agregam importante risco perioperatório às cirurgias vasculares, mesmo de caráter eletivo, aumentando significativamente a morbimortalidade. Faz-se necessário realizar melhor avaliação pré-operatória na tentativa de prever quais serão os pacientes que desenvolverão tais síndromes, haja vista que os atuais algoritmos utilizados não demonstram boa sensibilidade para detectar estes eventos. Alguns novos scores de predição de risco vêm sendo propostos e estão em avaliação. Este trabalho traz dois exames que se baseiam na fisiopatologia comum destas síndromes: A Dilatação Mediada pelo Fluxo (FMD), um marcador da função endotelial, e a Avaliação da Agregabilidade Plaquetária. Mostramos que a Agregabilidade Plaquetária avaliada antes da cirurgia foi relacionada a maior risco de desenvolver tais eventos e com pior desfecho. Estudos futuros devem avaliar se a agregabilidade plaquetária pode realmente funcionar como preditor de Injúria Renal Aguda. Além disso, mostramos que a Injúria Renal agrega, como fator independente, importante piora no prognóstico desses pacientes no pós-operatório com maior tempo de internação hospitalar e maior mortalidade. Novos estudos são necessários para confirmar tais achados. 


\section{REFERÊNCIAS}

1. de Mendonça A, Vincent JL, Suter PM, Moreno R, Dearden NM, Antonelli M, et al. Acute renal failure in the ICU: risk factors and outcome evaluated by the SOFA score. Intensive Care Med. 2000;26(7):915-21.

2. Metnitz PG, Krenn CG, Steltzer H, Lang T, Ploder J, Lenz K, et al. Effect of acute renal failure requiring renal replacement therapy on outcome in critically ill patients. Crit Care Med. 2002;30(9):2051-8.

3. Bellomo R, Ronco C, Kellum JA, Mehta RL, Palevsky P, workgroup ADQI. Acute renal failure - definition, outcome measures, animal models, fluid therapy and information technology needs: the Second International Consensus Conference of the Acute Dialysis Quality Initiative (ADQI) Group. Crit Care. 2004;8(4):R204-12.

4. Ronco C, Levin A, Warnock DG, Mehta R, Kellum JA, Shah S, et al. Improving outcomes from acute kidney injury (AKI): Report on an initiative. Int J Artif Organs. 2007;30(5):373-6.

5. Joannidis M, Metnitz B, Bauer P, Schusterschitz N, Moreno R, Druml W, et al. Acute kidney injury in critically ill patients classified by AKIN versus RIFLE using the SAPS 3 database. Intensive Care Med. 2009;35(10):1692-702.

6. Kellum J, Lameire N, Aspelin P, Barsoum RS, Burdmann EA, Goldstein SL, et al. KDIGO - Kidney Disease Improving Global Outcomes. Kidney International Suplements [Internet]. 2012; 2(1):[1-138 pp.].

7. Molitoris BA, Sutton TA. Endothelial injury and dysfunction: role in the extension phase of acute renal failure. Kidney Int. 2004;66(2):496-9.

8. Wen X, Murugan R, Peng Z, Kellum JA. Pathophysiology of acute kidney injury: a new perspective. Contrib Nephrol. 2010;165:39-45.

9. Basile DP. The endothelial cell in ischemic acute kidney injury: implications for acute and chronic function. Kidney Int. 2007;72(2):151-6.

10. Sutton TA, Fisher CJ, Molitoris BA. Microvascular endothelial injury and dysfunction during ischemic acute renal failure. Kidney Int. 2002;62(5):1539-49.

11. Libby P, Ridker PM, Hansson GK, Atherothrombosis LTNo. Inflammation in atherosclerosis: from pathophysiology to practice. J Am Coll Cardiol. 2009;54(23):2129-38.

12. Gheorghiade M, Zannad F, Sopko G, Klein L, Piña IL, Konstam MA, et al. Acute heart failure syndromes: current state and framework for future research. Circulation. 2005;112(25):3958-68.

13. Ronco C, McCullough P, Anker SD, Anand I, Aspromonte N, Bagshaw SM, et al. Cardio-renal syndromes: report from the consensus conference of the acute dialysis quality initiative. Eur Heart J. 2010;31(6):703-11.

14. Cruz DN. Cardiorenal syndrome in critical care: the acute cardiorenal and renocardiac syndromes. Adv Chronic Kidney Dis. 2013;20(1):56-66.

15. Chuasuwan A, Kellum JA. Cardio-renal syndrome type 3: epidemiology, pathophysiology, and treatment. Semin Nephrol. 2012;32(1):31-9. 
16. Daemen MA, van 't Veer C, Denecker G, Heemskerk VH, Wolfs TG, Clauss M, et al. Inhibition of apoptosis induced by ischemia-reperfusion prevents inflammation. J Clin Invest. 1999;104(5):541-9.

17. Kelly KJ. Distant effects of experimental renal ischemia/reperfusion injury. J Am Soc Nephrol. 2003;14(6):1549-58.

18. Bryant D, Becker L, Richardson J, Shelton J, Franco F, Peshock R, et al. Cardiac failure in transgenic mice with myocardial expression of tumor necrosis factor-alpha. Circulation. 1998;97(14):1375-81.

19. Brown LC, Thompson SG, Greenhalgh RM, Powell JT, participants EARt. Incidence of cardiovascular events and death after open or endovascular repair of abdominal aortic aneurysm in the randomized EVAR trial 1. Br J Surg. 2011;98(7):935-42.

20. Cuypers PW, Gardien M, Buth J, Peels CH, Charbon JA, Hop WC. Randomized study comparing cardiac response in endovascular and open abdominal aortic aneurysm repair. Br J Surg. 2001;88(8):1059-65.

21. Detrenis S, Meschi M, Musini S, Savazzi G. Lights and shadows on the pathogenesis of contrast-induced nephropathy: state of the art. Nephrol Dial Transplant. 2005;20(8):1542-50.

22. Borissoff $\mathrm{JI}$, Spronk HM, ten Cate H. The hemostatic system as a modulator of atherosclerosis. N Engl J Med. 2011;364(18):1746-60.

23. Wisman PP, Roest M, Asselbergs FW, de Groot PG, Moll FL, van der Graaf $Y$, et al. Platelet-reactivity tests identify patients at risk of secondary cardiovascular events: a systematic review and meta-analysis. J Thromb Haemost. 2014;12(5):736-47.

24. Kuliczkowski W, Witkowski A, Polonski L, Watala C, Filipiak K, Budaj A, et al. Interindividual variability in the response to oral antiplatelet drugs: a position paper of the Working Group on antiplatelet drugs resistance appointed by the Section of Cardiovascular Interventions of the Polish Cardiac Society, endorsed by the Working Group on Thrombosis of the European Society of Cardiology. Eur Heart J. 2009;30(4):426-35.

25. Green DJ, Jones H, Thijssen D, Cable NT, Atkinson G. Flow-mediated dilation and cardiovascular event prediction: does nitric oxide matter? Hypertension. 2011;57(3):363-9.

26. Martin BJ, Anderson TJ. Risk prediction in cardiovascular disease: the prognostic significance of endothelial dysfunction. Can J Cardiol. 2009;25 Suppl A:15A-20A.

27. Roman MJ, Naqvi TZ, Gardin JM, Gerhard-Herman M, Jaff M, Mohler E, et al. Clinical application of noninvasive vascular ultrasound in cardiovascular risk stratification: a report from the American Society of Echocardiography and the Society of Vascular Medicine and Biology. J Am Soc Echocardiogr. 2006;19(8):943-54.

28. Gaião S, Cruz DN. Baseline creatinine to define acute kidney injury: is there any consensus? Nephrol Dial Transplant. 2010;25(12):3812-4. 
29. Siew ED, Matheny ME, Ikizler TA, Lewis JB, Miller RA, Waitman LR, et al. Commonly used surrogates for baseline renal function affect the classification and prognosis of acute kidney injury. Kidney Int. 2010;77(6):536-42.

30. Lewington A, Kanagasundaram S. Renal Association Clinical Practice Guidelines on acute kidney injury. Nephron Clin Pract. 2011;118 Suppl 1:c349-90.

31. Calderaro D. Análise funcional do endotélio no perioperatório de cirurgias vasculares: Universidade de São Paulo; 2008.

32. Lee TH, Marcantonio ER, Mangione CM, Thomas EJ, Polanczyk CA, Cook EF, et al. Derivation and prospective validation of a simple index for prediction of cardiac risk of major noncardiac surgery. Circulation. 1999;100(10):1043-9.

33. Eagle KA, Berger PB, Calkins H, Chaitman BR, Ewy GA, Fleischmann KE, et al. ACC/AHA guideline update for perioperative cardiovascular evaluation for noncardiac surgery--executive summary: a report of the American College of Cardiology/American Heart Association Task Force on Practice Guidelines (Committee to Update the 1996 Guidelines on Perioperative Cardiovascular Evaluation for Noncardiac Surgery). J Am Coll Cardiol. 2002;39(3):542-53.

34. Cannon CP, Brindis RG, Chaitman BR, Cohen DJ, Cross JT, Drozda JP, et al. 2013 ACCF/AHA key data elements and definitions for measuring the clinical management and outcomes of patients with acute coronary syndromes and coronary artery disease: a report of the American College of Cardiology Foundation/American Heart Association Task Force on Clinical Data Standards (Writing Committee to Develop Acute Coronary Syndromes and Coronary Artery Disease Clinical Data Standards). Crit Pathw Cardiol. 2013;12(2):65-105.

35. Hobson C, Singhania G, Bihorac A. Acute Kidney Injury in the Surgical Patient. Crit Care Clin. 2015;31(4):705-23.

36. Ellenberger C, Schweizer A, Diaper J, Kalangos A, Murith N, Katchatourian G, et al. Incidence, risk factors and prognosis of changes in serum creatinine early after aortic abdominal surgery. Intensive Care Med. 2006;32(11):1808-16.

37. Nowygrod R, Egorova N, Greco G, Anderson P, Gelijns A, Moskowitz A, et al. Trends, complications, and mortality in peripheral vascular surgery. J Vasc Surg. 2006;43(2):205-16.

38. Alamartine E, Phayphet M, Thibaudin D, Barral FG, Veyret C. Contrast mediuminduced acute renal failure and cholesterol embolism after radiological procedures: incidence, risk factors, and compliance with recommendations. Eur J Intern Med. 2003;14(7):426-31.

39. Tallgren M, Niemi T, Pöyhiä R, Raininko E, Railo M, Salmenperä M, et al. Acute renal injury and dysfunction following elective abdominal aortic surgery. Eur $\mathrm{J}$ Vasc Endovasc Surg. 2007;33(5):550-5.

40. Romagnoli S, Ricci Z. Postoperative acute kidney injury. Minerva Anestesiol. 2015;81(6):684-96.

41. Kashani K, Steuernagle JH, Akhoundi A, Alsara A, Hanson AC, Kor DJ. Vascular Surgery Kidney Injury Predictive Score: A Historical Cohort Study. J Cardiothorac Vasc Anesth. 2015;29(6):1588-95. 
42. Harris DG, Koo G, McCrone MP, Weltz AS, Chiu WC, Sarkar R, et al. Acute Kidney Injury in Critically III Vascular Surgery Patients is Common and Associated with Increased Mortality. Front Surg. 2015;2:8.

43. Hollenberg NK, Epstein M, Rosen SM, Basch RI, Oken DE, Merrill JP. Acute oliguric renal failure in man: evidence for preferential renal cortical ischemia. Medicine (Baltimore). 1968;47(6):455-74.

44. Mattson DL, Lu S, Cowley AW. Role of nitric oxide in the control of the renal medullary circulation. Clin Exp Pharmacol Physiol. 1997;24(8):587-90.

45. Shechter M, Shechter A, Koren-Morag N, Feinberg MS, Hiersch L. Usefulness of brachial artery flow-mediated dilation to predict long-term cardiovascular events in subjects without heart disease. Am J Cardiol. 2014;113(1):162-7.

46. Celermajer DS, Sorensen KE, Gooch VM, Spiegelhalter DJ, Miller OI, Sullivan ID, et al. Non-invasive detection of endothelial dysfunction in children and adults at risk of atherosclerosis. Lancet. 1992;340(8828):1111-5.

47. Thambyrajah J, Landray MJ, McGlynn FJ, Jones HJ, Wheeler DC, Townend JN. Abnormalities of endothelial function in patients with predialysis renal failure. Heart. 2000;83(2):205-9.

48. Woo KS, Chook P, Yu CW, Sung RY, Qiao M, Leung SS, et al. Effects of diet and exercise on obesity-related vascular dysfunction in children. Circulation. 2004;109(16):1981-6.

49. Yeboah J, Crouse JR, Hsu FC, Burke GL, Herrington DM. Brachial flowmediated dilation predicts incident cardiovascular events in older adults: the Cardiovascular Health Study. Circulation. 2007;115(18):2390-7.

50. Santos-García D, Blanco M, Serena J, Rodríguez-Yáñez M, Leira R, Castillo J. Impaired brachial flow-mediated dilation is a predictor of a new-onset vascular event after stroke. Cerebrovasc Dis. 2011;32(2):155-62.

51. Tripolino C, Irace C, Carallo C, De Franceschi MS, Della Valle E, Gnasso A. Blood urea impairs brachial artery flow mediated dilation. Int Angiol. 2015;34(4):392-7.

52. Dorgalaleh A, Mahmudi M, Tabibian S, Khatib ZK, Tamaddon GH, Moghaddam $\mathrm{ES}$, et al. Anemia and thrombocytopenia in acute and chronic renal failure. Int $\mathrm{J}$ Hematol Oncol Stem Cell Res. 2013;7(4):34-9.

53. Boccardo P, Remuzzi G, Galbusera M. Platelet dysfunction in renal failure. Semin Thromb Hemost. 2004;30(5):579-89.

54. Gremmel T, Müller M, Steiner S, Seidinger D, Koppensteiner R, Kopp CW, et al. Chronic kidney disease is associated with increased platelet activation and poor response to antiplatelet therapy. Nephrol Dial Transplant. 2013;28(8):2116-22.

55. Angiolillo DJ, Bernardo E, Capodanno D, Vivas D, Sabaté M, Ferreiro JL, et al. Impact of chronic kidney disease on platelet function profiles in diabetes mellitus patients with coronary artery disease taking dual antiplatelet therapy. $J$ Am Coll Cardiol. 2010;55(11):1139-46.

56. Woo JS, Kim W, Lee SR, Jung KH, Kim WS, Lew JH, et al. Platelet reactivity in patients with chronic kidney disease receiving adjunctive cilostazol compared with a high-maintenance dose of clopidogrel: results of the effect of platelet 
inhibition according to clopidogrel dose in patients with chronic kidney disease (PIANO-2 CKD) randomized study. Am Heart J. 2011;162(6):1018-25.

57. Muller C, Caillard S, Jesel L, El Ghannudi S, Ohlmann P, Sauleau E, et al. Association of estimated GFR with platelet inhibition in patients treated with clopidogrel. Am J Kidney Dis. 2012;59(6):777-85.

58. Goren O, Matot I. Perioperative acute kidney injury. Br J Anaesth. 2015;115 Suppl 2:ii3-14.

59. Walsh M, Devereaux PJ, Garg AX, Kurz A, Turan A, Rodseth RN, et al. Relationship between intraoperative mean arterial pressure and clinical outcomes after noncardiac surgery: toward an empirical definition of hypotension. Anesthesiology. 2013;119(3):507-15.

60. Sun LY, Wijeysundera DN, Tait GA, Beattie WS. Association of intraoperative hypotension with acute kidney injury after elective noncardiac surgery. Anesthesiology. 2015;123(3):515-23.

61. Brienza N, Giglio MT, Marucci M, Fiore T. Does perioperative hemodynamic optimization protect renal function in surgical patients? A meta-analytic study. Crit Care Med. 2009;37(6):2079-90.

62. Garg AX, Kurz A, Sessler DI, Cuerden M, Robinson A, Mrkobrada M, et al. Perioperative aspirin and clonidine and risk of acute kidney injury: a randomized clinical trial. JAMA. 2014;312(21):2254-64.

63. Stegnar M. Platelet function tests and resistance to antiplatelet therapy. Srp Arh Celok Lek. 2010;138 Suppl 1:59-63.

64. Flu WJ, Schouten O, van Kuijk JP, Poldermans D. Perioperative cardiac damage in vascular surgery patients. Eur J Vasc Endovasc Surg. 2010;40(1):1-8.

65. Saratzis A, Harrison S, Barratt J, Sayers RD, Sarafidis PA, Bown MJ. Intervention Associated Acute Kidney Injury and Long-Term Cardiovascular Outcomes. Am J Nephrol. 2015;42(4):285-94. 